\title{
LA TECNOLOGÍA CERÁMICA EN OCUPACIONES DEL HOLOCENO TARDÍO (ca. 1900 AÑOS AP) EN EL VALLE DE ONGAMIRA (CÓRDOBA, ARGENTINA)
}

\author{
Andrés Robledo ${ }^{*}$ Leticia Gasparotti ${ }^{* *}$
}

Fecha de recepción: 14 de enero de 2021

Fecha de aceptación: 13 de abril de 2021

\section{RESUMEN}

Se presentan los primeros resultados obtenidos del análisis del conjunto cerámico recuperado en las excavaciones del sitio Parque Natural Ongamira 1, localizado en el valle de Ongamira (Ischilín, Córdoba, Argentina). Se propone indagar sobre su manufactura, uso y descarte de acuerdo a los contextos identificados, para realizar los primeros aportes sobre las prácticas de producción y uso de esta materialidad para el valle. A partir de los estudios macroscópicos y microscópicos se pudo identificar la presencia de al menos seis vasijas en diferentes contextos de ocupación, las cuales muestran diferencias tanto en sus pastas como en los acabados superficiales y decoraciones. Los análisis microscópicos de petrografía de pastas nos llevaron a identificar cuatro tipos de variantes en su composición, dos de ellas con posible origen local. Esto permite indagar en las relaciones existentes entre los habitantes del valle hacia los 1900 años AP a través de las características de los objetos cerámicos utilizados.

Palabras clave: tecnología cerámica - Sierras Pampeanas Australes - Holoceno Tardío petrografía

\footnotetext{
* Instituto de Antropología de Córdoba, Museo de Antropología, Facultad de Filosofía y Humanidades, Consejo Nacional de Investigaciones Científicas y Técnicas, Universidad Nacional de Córdoba. E-mail: and.robledo@ffyh.unc.edu.ar

** Centro de Investigaciones y Transferencia de Catamarca, Universidad Nacional de Catamarca, Consejo Nacional de Investigaciones Científicas y Técnicas. E-mail: Igasparotti@arqueo.unca.edu.ar
} 


\section{POTTERY TECHNOLOGY IN LATE HOLOCENE OCCUPATIONS (ca. 1900 YEARS BP) IN THE ONGAMIRA VALLEY (CÓRDOBA, ARGENTINA)}

\section{ABSTRACT}

We present the first analytical results of the pottery assemblage retrieved from the Parque Natural Ongamira 1 site excavations, located in the Ongamira valley (Ischilin, Córdoba, Argentina). The objective of this paper is to inquire into the production, use and disposal of this record, in accordance with the identified contexts, in order to make the first contributions to the production and use practices in relation to this materiality in this valley. From macroscopic and microscopic studies, we were able to identify the presence of at least six vessels in different occupation contexts, with differences both in their pastes and in surface finishes and decorations. Using microscopic petrography analyses, we were able to identify four types of paste composition variants; two of these may have been from a local source. By studying the ceramic objects used by those who inhabited the valley around 1900 BP, we can explore the relationships that existed among them.

Keywords: pottery technology - Austral Pampeans Hills - Late Holocene - petrography

\section{INTRODUCCIÓN}

Las investigaciones en el valle de Ongamira (Córdoba, Argentina) han permitido caracterizar las ocupaciones humanas para distintos momentos del Holoceno Tardío y finales del Holoceno Medio (Menghin y González 1954; Cattáneo e Izeta 2016) para el sector norte de las Sierras Pampeanas Australes. En los últimos años, se han realizado avances en la localización de nuevos lugares en el valle con evidencias de haber sido habitados, tales como aleros y espacios al aire libre identificados como fuentes de aprovisionamiento de cuarzo para la talla, lugares de molienda con la presencia de morteros, entre otros (Cattáneo et al. 2020; Conte y Robledo 2020; Robledo 2020). Esto ha permitido caracterizar las ocupaciones humanas desde la cacería y consumos de animales (Izeta et al. 2014; Costa 2015; entre otros), la manufactura y uso de instrumentos líticos (Caminoa 2016; Cattáneo et al. 2017; Robledo et al. 2018, entre otros) así como las prácticas de uso y manejo del fuego (Robledo 2016, 2020), entre otras líneas desarrolladas.

En el marco de estos estudios, la tecnología cerámica utilizada por las poblaciones del pasado continúa siendo un interrogante en el valle, ya que se cuenta solo con las interpretaciones realizadas por Menghin y González (1954) y los estudios llevados a cabo en áreas aledañas (e.g. Laguens 1999; Traktman et al. 2020). En los últimos años, en el marco del proyecto "Aproximaciones interdisciplinarias para el estudio arqueológico de sociedades cazadoras-recolectoras, Córdoba, Argentina", dirigido por la doctora Roxana Cattáneo y el doctor Andrés Izeta, se han retomado las investigaciones sistemáticas en Parque Natural Ongamira 1 (en adelante PNO 1) con el fin de profundizar el conocimiento de las ocupaciones asociadas a los espacios de aleros para comprender los cambios en los modos de vida a lo largo del tiempo. En ese sentido, el objetivo de este trabajo es caracterizar el conjunto cerámico recuperado en las últimas excavaciones para así indagar sobre su manufactura, uso y descarte de acuerdo a los contextos identificados. Esto nos permitirá aportar la primera información detallada sobre las prácticas de producción y uso de esta materialidad para el valle, así como también profundizar en las características de las ocupaciones de PNO 1 hacia finales del Holoceno. 


\section{DESCRIPCIÓN DEL ÁREA DE ESTUDIO}

Nuestra área de trabajo se ubica en el límite septentrional de las Sierras Chicas, casi al límite con las Sierras del Norte, unidades que integran el sector noroeste de las Sierras Pampeanas Australes (Carignano 1999) (figura 1). El valle de Ongamira tiene una orientación longitudinal este-oeste originada por las depresiones tectónicas comprendidas entre las fallas inversas responsables del ascenso de la sierra (Zárate 2016). Se desarrolla sobre un conglomerado del basamento cristalino de Gondwana e incluye una formación cretácica de arenisca roja (Carignano 1999).

Específicamente para este trabajo, resulta relevante detallar las características de la geología local y regional. En este sentido, el valle colinda hacia el norte con el Complejo Ígneo Sierra Norte (referencia 5, 6 y 7 en la figura 1) caracterizado por la presencia de granodiorita (7) rocas metabásicas (6), paragneis muscovítico y ortogneises granítico (5). Se conforma como uno de los rasgos más importantes de la región, compuesto por granitoides, los que desarrollan una foliación gnéisica de variada intensidad, definida por alineación de biotita y hornblenda, y de enclaves máficos presentes en esta fase magmática. Los depósitos sedimentarios corresponden a la formación Saldán y al Conglomerado los Terrones (referencia 16 en figura 1), ambos de edad Cretácica, caracterizados por areniscas muy finas, conglomerádicas, castaño rojizas y tenaces que se disponen en bancos o estratos finos a medianos (Piovano 1996; Candini et al. 2001; Franzen 2016; Zárate 2016).

En las inmediaciones del sitio, también se encuentra la Formación Copacabana, conformada por areniscas, fangolitas y ortoconglomerados oligopolimícticos. También se debe mencionar al Calcrete de Avellaneda, formado por limos arenosos, calcretes y silcretes. Además, se debe considerar la Formación Chuña, compuesta por limos loéssico, loess, limos arenosos y arenas finas con lentes de arenas gruesas y gravas.

Relacionado con la producción de objetos cerámicos, debemos mencionar que existen avances en el estudio sobre yacimientos de arcillas. Por un lado, Alonso y Gaido (2018:4) realizaron la descripción geológica de algunos presentes en el valle de Ongamira y alrededores. Junto con
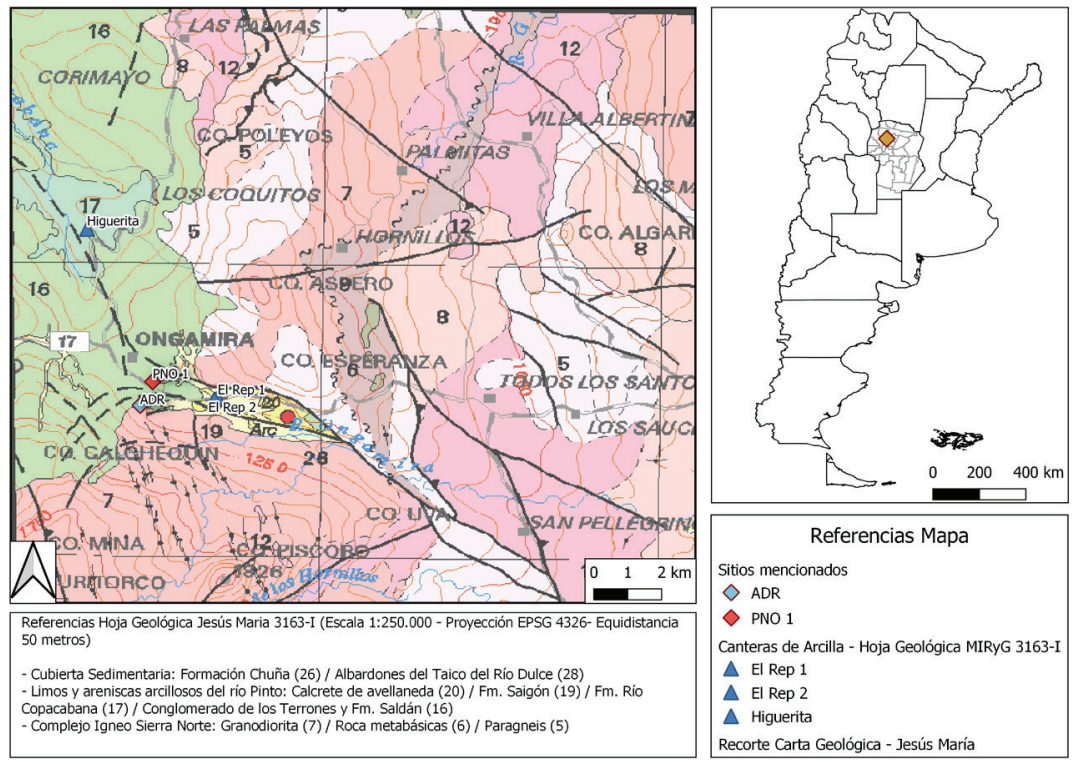

Figura 1. Localización de sitios arqueológicos PNO 1, ADR y canteras de arcillas registradas por Alonso y Gaido (2018). Recorte de Hoja geológica Jesús María 3163-I sobre la zona de estudio (Candini et al. 2001) 
esto, podemos referir el trabajo realizado por Bertolino y colaboradores (2010) sobre fuentes de arcillas localizadas en el valle de Copacabana. A partir de estudios DRX, ICP/MS y FRX, los autores analizan de manera comparativa los yacimientos de arcilla y el material arqueológico resultante de los estudios de Laguens (1999). En los últimos años se están realizando avances en el estudio de las prácticas alfareras actuales y la caracterización físico-química de las materias primas utilizadas por los pobladores de las sierras de Córdoba (Collo et al. 2019).

El sitio arqueológico bajo estudio, el alero PNO 1, se encuentra emplazado a 1.222 m s.n.m. en uno de los afloramientos rocosos de la arenisca rojiza localizados más al norte del valle (figura 1). Presenta una orientación este-oeste con abertura hacia el sur, posee más de $30 \mathrm{~m}$ de largo y el ancho entre la pared del alero y la línea de goteo varía entre los 2 y los $4 \mathrm{~m}$. Está rodeado de una vegetación arbustiva baja. Se excavaron dos cuadrículas que cubren una superficie de $10 \mathrm{~m}^{2}$ en la parte interna del alero, donde se identificaron 86 unidades estratigráficas diferenciadas por su composición sedimentaria y las evidencias de cultura material (figura 2).

Hasta el momento, las investigaciones en PNO 1 permitieron profundizar en distintas líneas de evidencias a lo largo de una secuencia de ocupación donde se pudieron identificar al menos a tres momentos durante Holoceno. En la mayor profundidad alcanzada se identificó la ocupación más temprana del alero, datada en $5782 \pm 24{ }^{14} \mathrm{C}$ años AP (YU-7751, carbón, Izeta et al. 2021), asociada a un evento de combustión con pocos restos óseos no identificados y lascas de cuarzo. En segundo lugar, se pueden mencionar aquellos registros de eventos de ocupación asociados a un fechado radiocarbónico de $2802 \pm 20{ }^{14} \mathrm{C}$ años AP (YU-7744, carbón Izeta et al. 2021). Para estos momentos ( $c a$. 2800-3600 años AP), se ha inferido la presencia de grupos humanos con una alta movilidad dentro del valle y la realización de múltiples actividades en los aleros, tales como la confección y uso de instrumental lítico asociado a la cacería de animales y al procesamiento de otros materiales como huesos y maderas. También se infirió la realización de actividades vinculadas a una cierta manera de habitar los aleros, con estrategias generalistas en la recolección de la leña y con la caza especializada de guanacos (Costa et al. 2017).

De acuerdo con los objetivos planteados en este trabajo, en esta oportunidad nos centramos en las ocupaciones más tardías del alero. Investigaciones sobre otras materialidades halladas para estas poblaciones han permitido interpretar la realización de diferentes actividades cotidianas como la manufactura de instrumentos líticos de cuarzo y silcretas en las etapas finales dentro de la secuencia de producción (Robledo et al. 2018). Además, las personas mantuvieron el aprovechamiento de animales como el guanaco, ciervos y en menor medida mamíferos más pequeños, así como también el empleo de leñas locales para la realización de fogatas, caracterizadas por la presencia de sectores de combustión estructurados con restos de carbón vegetal y lentes de ceniza in situ (Robledo 2020). En el registro de estos contextos fueron hallados, además, restos de alfarería asociados a un fechado radiocarbónico de $1905 \pm 20{ }^{14} \mathrm{C}$ años AP (YU-7746, carbón, Izeta et al. 2021).

En este caso, es la primera ocasión en la que se asocia la cerámica a una cronología absoluta para el valle, aunque también se han registrado restos de material cerámico desde los niveles superficiales. Por tal razón, consideramos en este trabajo todos los fragmentos cerámicos recuperados, esperando a futuro poder conocer la cronología de las ocupaciones más tardías del alero. Al respecto, investigaciones que se han desarrollado en todo el valle en los últimos años permitieron conocer los momentos en que las poblaciones lo habitaron (Cattáneo et al. 2013; Izeta et al. 2016; Izeta et al. 2021). De momento, el fechado más tardío fue obtenido en el sitio Alero Deodoro Roca (en adelante ADR) de ca. 650 años AP, ubicado en cercanías de PNO 1 (figura 1). 
A. Robledo y L. Gasparotti - La tecnología cerámica en ocupaciones del Holoceno Tardío ...

ANTECEDENTES DE ESTUDIOS CERÁMICOS EN LAS SIERRAS PAMPEANAS AUSTRALES

La tecnología cerámica ha sido objeto de investigaciones muy diversas en el marco regional de las Sierras Pampeanas Australes (e.g. Ameghino 1885; González 1960; Argüello de Dorsch 1983; Gambier 1998; Laguens 1999; Pastor 2006; Dantas y Figueroa 2008; Medina 2008; Rocchietti y Ribero 2017; Traktman et al. 2020; Carosio et al. 2021; entre otros). Uno de los principales aportes ha sido el de Serrano (1945), quien orientó la clasificación de tipos cerámicos a partir de atributos formales para caracterizar los grupos culturales. Por su parte, Rex González (1952) definió cuatro tipos cerámicos para la región de Pampa de Olaen, obteniendo una base interpretativa que sirvió, años más tarde, para interpretar la alfarería recuperada en el valle de Ongamira.

Las excavaciones que realizó junto con Menghin (Menghin y González 1954) durante la década de 1940 y principios de 1950, les permitieron recuperar fragmentos cerámicos de sitios al aire libre (denominados A, B, C y D) y en el ADR. En este último, que fue el lugar más explorado y desde donde se sentaron parte de las bases de la cronología de ocupaciones para todas las Sierras Centrales (González 1960), se recuperaron cerca de 50 tiestos entre los que se identificaron los tipos de alfarería Olaen monocroma, San Roque Tosca, así como fragmentos grabados e improntas de moldes de cestería (Menghin y González 1954:219-221). Sobre esta base, y considerando el resto de las evidencias procedentes de otras regiones de las Sierras Centrales, propusieron que la mayoría de los fragmentos corresponderían a vasos de tamaños pequeños a medianos, de acuerdo a las dimensiones de los fragmentos, probablemente importados desde otras regiones por actividades de intercambio.

Más recientemente, en cercanías de nuestra región de estudio, se llevaron a cabo trabajos sobre el valle de Copacabana, donde Laguens (1999) estudió diferentes contextos del Holoceno Tardío y de contacto prehispánico. Propuso la elaboración expeditiva de alfarería -caracterizada por la presencia de pastas variadas- con el objetivo de cubrir necesidades inmediatas. Se habría tratado de grupos con un aprovisionamiento de recursos de manera diversificada, quienes habrían aprovechado los distintos ambientes del valle y las zonas aledañas. En términos generales, para los diferentes conjuntos cerámicos no habría existido una regularidad en las formas y en la calidad, por lo que habría existido a una manufactura sujeta a mucha variación individual de acuerdo a las habilidades del artesano (Laguens y Bonnin 2009). Por su parte, Traktman y colaboradores (2020) analizaron material procedente de los sitios El Ranchito, Los Tártagos, Cachipuri y Arroyo Saguión 1 asociados a la cuenca del río Copacabana. Los estudios petrográficos realizados por estos autores indican la existencia de variabilidad composicional en las pastas, lo que sugiere un uso diferencial de materias primas por parte de los alfareros de la región. Destacan la presencia de dos grandes conjuntos de pastas, uno con inclusiones de rocas volcánicas y otro con ausencia de ellas.

En el marco regional de las Sierras Pampeanas Australes, la cronología de las ocupaciones humanas asociadas a tecnología cerámica aún es un aspecto que necesita mayor desarrollo (Izeta et al. 2017). Se puede mencionar el sitio Alto 3 que tiene un primer componente superficial asociado a material lítico, fragmentos de cerámica y una estatuilla (Roldán et al. 2005) de ca. 670 años AP. Por su parte, las investigaciones de Dantas y Figueroa (2008), Medina (2008) y Pastor (2006) permitieron dar una mayor profundidad a los estudios de la región. Los contextos cerámicos de los sitios Talainín 2 y Tala Cañada 1 se dataron entre ca. 700 y 900 años AP (Pastor 2006). En tanto, para la zona de Pampa de Achala, en el sitio Río Yuspe 14 se identificó una estructura de combustión con material cerámico en ca. 600 años AP (Pastor 2006). Mientras que en el sitio Río Yuspe 11 se recuperaron fragmentos cerámicos asociados a ocupaciones de $c a$. 1100 y 1500 años AP (Pastor 2006:175). A esto se pueden sumar las investigaciones de Medina (2006), especialmente en los sitios C. Pun. 39 con contextos cerámicos datados entre ca. 520 y 850 años AP; y los trabajos en Puesto La Esquina 1 en ca. 365 años AP (Medina 2010). En tanto, 
para el sector austral de las sierras, los aportes del equipo de Rochietti (Rocchietti y Ribero 2018) permiten caracterizar las ocupaciones en un amplio período de ocupación (entre ca. 290 y 3800 años AP) donde la cerámica es una de las pocas materialidades recuperadas en las excavaciones.

Por último, Carosio y colaboradores (2021) analizaron la petrografía de fragmentos cerámicos procedentes de sitios del valle de Punilla, Salsacate y Pampa de Olaen con el interés de estudiar la movilidad y las estrategias de elaboración de los artefactos cerámicos para momentos tardíos (1500-360 años AP) (Medina et al. 2016). A partir del estudio de 25 muestras de cortes petrográficos, identificaron nueve fábricas diferentes y proponen que las vasijas eran realizadas con material procedente de las cercanías de los sitios, los cuales probablemente habrían formado parte de los circuitos de movilidad anual de las personas con una estrategia donde la adopción de cultivos de plantas no necesariamente llevó a un sedentarismo por completo.

\section{MATERIALES Y MÉTODOS}

En este trabajo consideramos la tecnología como un fenómeno social total, un campo en donde las personas y sus relaciones se expresan, generan y reproducen socialmente a través de las prácticas sociales (Lemonnier 1992; Dobres y Hoffman 1994; Dobres 1999; Hoffman 1999). Estas prácticas se traducen en elecciones tecnológicas observables en el registro material (Lemonnier 1993), siendo estas elecciones las que refieren al contexto social en el cual se desarrolló la práctica de elaboración de un objeto, en este caso la cerámica.

La excavación de PNO 1 fue registrada mediante la descripción de unidades estratigráficas (Harris 1991) lo que permitió la interpretación de la secuencia de depositación de los sedimentos de origen natural y cultural. A partir de esto, se pudo construir un diagrama de unidades que permite la interpretación de los distintos eventos de ocupación en el tiempo (figura 2).

Se recuperó un total de 44 fragmentos, procedentes tanto de excavación estratigráfica como de la limpieza de una zanja producida por acción del agua. La mayoría de los fragmentos estaban distribuidos en ocho unidades estratigráficas (sensu Harris 1991) que alcanzaron una profundidad de excavación hasta $15 \mathrm{~cm}$ (tabla 1 y figura 2). Ya que se trata de un alero con potencialidad es-

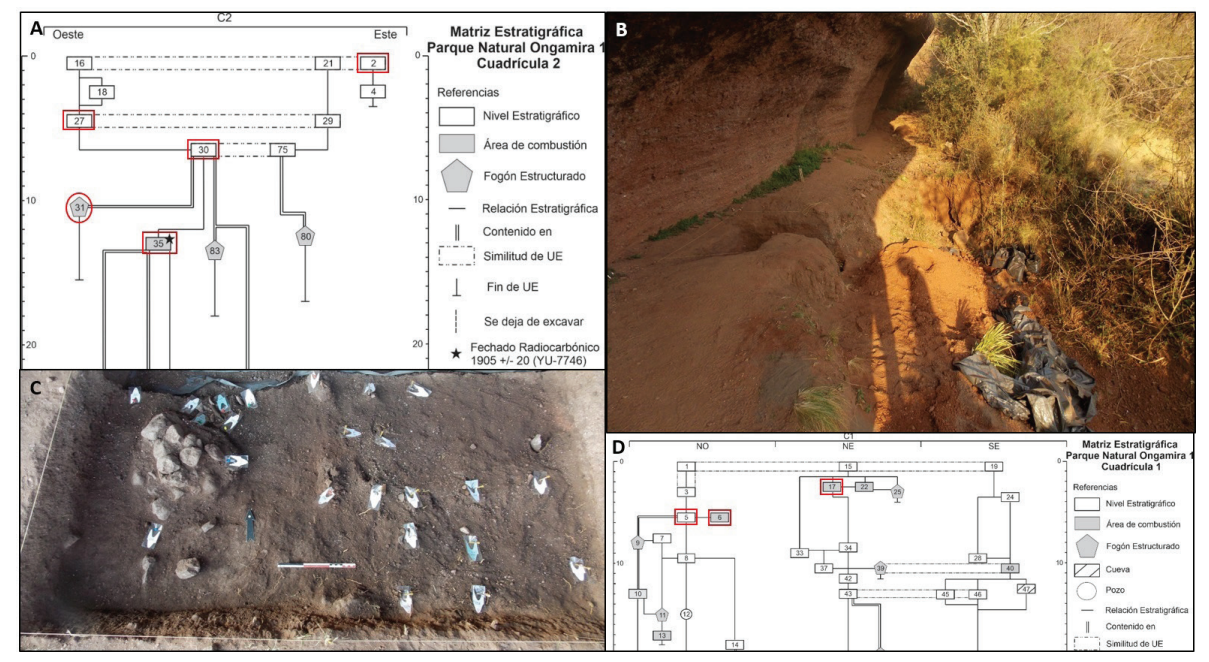

Figura 2. Registro del sitio Parque Natural Ongamira 1. A y D. Recorte de matriz estratigráfica de las cuadrículas 1 y 2 (en rojo están las unidades con material cerámico). B. Vista general del alero con la cuadrícula 1. C. Unidad estratigráfica 35 asociada al fechado ca. 1900 años AP 
tratigráfica de al menos dos metros (Robledo 2020), esta materialidad, distribuida en los niveles más superficiales, pudo haber sido más afectada por los procesos postdepositacionales como el pisoteo de animales, las actividades turísticas y la acción del agua durante las lluvias.

Tabla 1. Fragmentos de cerámica distribuidos por unidad estratigráfica en el sitio PNO 1 (ver más detalle en Robledo 2020:233)

\begin{tabular}{|c|c|c|}
\hline $\mathbf{U E}$ & Descripción Unidad Estratigráfica & $\mathbf{N}^{\circ}$ Fragmentos \\
\hline 2 & $\begin{array}{l}\text { Cuadrícula 2. Sector NO. Unidad superficial compactada por el pisoteo } \\
\text { y la caída de agua. Se recuperaron fragmentos óseos pequeños, carbón, } \\
\text { tiestos y lascas de cuarzo. }\end{array}$ & 5 \\
\hline 5 & $\begin{array}{l}\text { Cuadrícula 1. Sector NO. Unidad matriz con presencia de carbón } \\
\text { disperso, restos óseos de distintos tamaños y fragmentos de cerámica. }\end{array}$ & 3 \\
\hline 6 & $\begin{array}{l}\text { Cuadrícula 1. Sector NO. Unidad contenida en la UE5. Se identifica } \\
\text { un cambio en la compactación con límites definidos y en el cual se } \\
\text { recuperan espículas de carbón concentradas, fragmentos de cerámica de } \\
\text { distintos tamaños y restos óseos. }\end{array}$ & 8 \\
\hline 17 & $\begin{array}{l}\text { Cuadrícula } 1 . \text { Sector NE. Unidad con sectores de carbón compactado, } \\
\text { restos óseos pequeños, lascas de cuarzo y fragmentos de cerámica. }\end{array}$ & 4 \\
\hline 27 & $\begin{array}{l}\text { Cuadrícula 2. Sector NO. Unidad en transición a la UE30, con presencia } \\
\text { de fragmentos cerámicos, restos óseos y material lítico disperso. }\end{array}$ & 4 \\
\hline 30 & $\begin{array}{l}\text { Cuadrícula 2. Sector NO. Unidad matriz con presencia de restos óseos } \\
\text { termoalterados, material lítico de cuarzo y fragmentos de cerámica. Está } \\
\text { por encima de la UE35 y contiene a los lentes de ceniza UE31 y UE60. }\end{array}$ & 5 \\
\hline 31 & $\begin{array}{l}\text { Cuadrícula 2. Sector NO. Lente de ceniza contenido en la UE30, se } \\
\text { recuperan fragmentos de cerámica. }\end{array}$ & 3 \\
\hline 35 & $\begin{array}{l}\text { Cuadrícula 2. Sector NO. Unidad matriz con presencia de restos } \\
\text { óseos termoalterados, fragmentos de carbón dispersos, material lítico } \\
\text { (punta de proyectil e instrumentos con filos formatizados) y tiestos. } \\
\text { Se recuperan fragmentos de valvas de moluscos dispersas. Se obtuvo } \\
\text { fechado radiocarbónico de } 1905+/-20 \text { años AP (YU-7746, carbón, } \\
\text { Izeta et al. 2021). }\end{array}$ & 5 \\
\hline RS & $\begin{array}{l}\text { Fragmentos recolectados en la superficie del sitio removidos por la } \\
\text { acción del agua y del pisoteo. }\end{array}$ & 3 \\
\hline Total & & 40 \\
\hline
\end{tabular}

La metodología aplicada para el análisis del material cerámico fue desarrollada en dos etapas, la primera realizada a nivel macroscópico (ojo desnudo y lupa de bajos aumentos), y la segunda a nivel microscópico (petrografía de pastas). Cabe aclarar que, aunque la totalidad del conjunto cerámico analizado es de carácter fragmentario, se consideró que tomar a los tiestos como unidad de análisis no es adecuado. Por lo tanto, se asociaron fragmentos en grupos que podrían responder a una misma pieza (Grupos de Fragmentos).

Esta separación fue realizada sobre la base de la observación macroscópica de variables referidas a diversas elecciones tecnológicas (Lemonnier 1993) tomadas durante distintas etapas de la manufactura (Cremonte 1983-85; Rye 1988; Sinopoli 1991; Orton et al. 1997; Zagorodny 2000). Para esto se observaron diversos atributos que refieren a la manufactura, como aquellos relacionados con el preparado de la arcilla, el levantado de la pieza, los tratamientos y acabados superficiales, la cocción y, finalmente, la existencia de marcas o trazas relacionadas con el uso 
y el descarte o depositación. Las semejanzas en dichas características permiten suponer, como primer acercamiento, que un grupo de fragmentos determinados podrían corresponder a un mismo objeto cerámico (Orton et al. 1997).

En este sentido, el remontaje de fragmentos es una vía válida para relacionar dos o más fragmentos con una vasija particular. Ahora, si esa posibilidad no existe, como fue este caso, también se pueden agrupar aquellos fragmentos que no remontan pero que, a simple vista, comparten características tecnológicas similares, como pastas, tratamientos de superficie o tipo de cocción. Dichas características pueden hacer suponer que grupos de fragmentos corresponden a un mismo objeto cerámico (Orton et al. 1997). Aunque la observación se realizó sobre cada fragmento individual, no implicó dejar de lado la categoría de Grupo de Fragmentos, ya que mediante esta elección metodológica fue posible generar una base de datos más completa y detallada, considerando que un mismo objeto cerámico puede presentar en distintas partes diferentes características tecnológicas. A partir de esto, se observó su forma, tamaño, espesor, tratamiento de la superficie, inclusiones y cavidades, entre otros.

Por su parte, la segunda etapa del estudio consistió en análisis petrográficos de pastas a partir de cortes delgados. Uno de los principales objetivos de estos estudios es lograr la caracterización composicional de las pastas, su clasificación, para obtener una aproximación a la procedencia de las materias primas mediante comparaciones con la geología local y la reconstrucción de las elecciones tecnológicas (Freestone 1991, 1995; Quinn 2013). Para esto se seleccionaron nueve fragmentos, considerados en este primer acercamiento como representativos de la variabilidad detectada en los Grupos de Fragmentos establecidos de forma macroscópica. Somos conscientes de que es una cantidad reducida de muestras, pero esperamos en próximas oportunidades sumar más análisis.

La descripción de las pastas al microscopio se realizó mediante el análisis de distribución modal de tres elementos: matriz, inclusiones y cavidades o poros. En cada corte se realizó un conteo de puntos (mínimo 300) recorriendo su extensión horizontalmente y cubriendo toda la superficie, contando a intervalos constantes los elementos sobre los cuales se posó la cruz del retículo (Pereyra Domingorena 2010). Durante este conteo también se tuvieron en cuenta los fondos de pasta o matrices y la determinación mineralógica de las inclusiones mayores a $10 \mu \mathrm{m}$. Al mismo tiempo, se registraron las formas, tamaños, angulosidad y esfericidad de las inclusiones no plásticas y de las cavidades (Cremonte 1996). Para este análisis se utilizó un microscopio de petrográfico de polarización marca Bio-Traza modelo XP-148PLT.

Una vez obtenidos los resultados del conteo de puntos se realizó el tratamiento estadístico de la información. Para ello, los porcentajes estimados de matriz, cavidades y de diversas inclusiones fueron procesados con el programa estadístico PAST V.3. Se aplicó un Análisis de Componentes Principales (ACP), seguido de un análisis estadístico de conglomerados jerárquicos, que posibilitó definir distintos tipos de pastas (Hammer et al. 2001). El primero, a pesar de contar con poca cantidad de muestras, nos brinda la posibilidad de establecer cuáles son los principales elementos que diferencian las muestras entre sí. El segundo, permitió diferenciar las relaciones que existen entre las muestras analizadas, en función de sus similitudes y disimilitudes (Cremonte 1996).

Este abordaje posibilita la segregación de tipos petrográficos o tipos de pastas, los cuales son definidos sobre la base de una sección delgada o un grupo de ellas que tienen una combinación específica de inclusiones, matriz arcillosa y poros, y que presenta alguna diferencia significativa respecto de otras muestras dentro del grupo estudiado. De esta forma, los tipos petrográficos de pastas están definidos por sus ingredientes constitutivos y por las formas en las cuales estas fueron preparadas y combinadas (Quinn 2013). 


\section{RESULTADOS}

\section{Descripción macroscópica}

Del total de fragmentos recuperados $(n=44)$, solo pudieron analizarse 40 , ya que los 4 restantes son de tamaño reducido. En la figura 4 pueden observarse las fotografías de algunos de los fragmentos estudiados. El conjunto, en general, se encuentra muy fragmentado, con tamaños mínimo de $1,31 \mathrm{~cm}$ y máximo de $5,74 \mathrm{~cm}$, mientras que la moda registrada fue de 1,63 cm (figura 3-A).

En cuanto a la identificación de las formas, en ningún caso se pudo asignar morfología ya que la mayoría de los fragmentos se corresponden con porciones indeterminadas ( $n=39)$ y solo un caso pudo ser asignado a un borde, cuyo diámetro estimado es de $18 \mathrm{~cm}$ de abertura. Sin embargo, no podemos afirmar que esta medición sea confiable, ya que el porcentaje del arco representado por este fragmento es del 2,85\% del total. En cuanto a su morfología, puede asimilarse a un borde con ángulo obtuso, es decir, evertido, con un labio de forma convexa.

Por otro lado, en la mayoría de los casos analizados $(n=38)$ no se pudo observar la técnica de trabajo o levantado de la pieza, solo dos fragmentos permitieron identificar la técnica de rodete. Estos presentan una ondulación clara en sus superficies que evidencia la superposición de los rollos. Otra variable para aportar a la descripción de la etapa de levantamiento de las piezas es el espesor de las paredes. Este dato resulta fundamental en la reconstrucción de las elecciones tecnológicas. El espesor de las paredes puede ayudar a vislumbrar el tamaño de la pieza, su peso general o el sector de la vasija a la que se está haciendo referencia, incluso al objetivo para el cual fue fabricada. Sin embargo, para este caso, dado el carácter fragmentario de la muestra no hemos podido avanzar demasiado en este sentido. Para el conjunto de PNO 1 se estableció que la moda es de 0,64 cm, mientras que el espesor mínimo es de 0,44 cm y el máximo de $1,18 \mathrm{~cm}$ (figura 3-C). Podríamos inferir que estos espesores en las paredes del conjunto habrían conformado un equipo cerámico de dimensiones intermedias, tal vez facilitando su transporte de un sitio a otro.

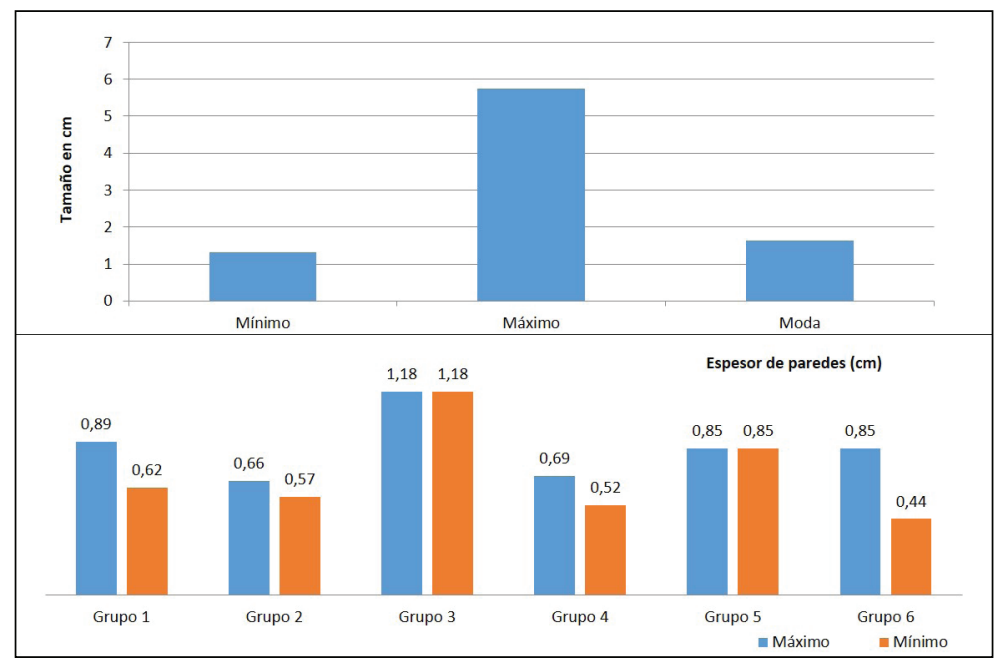

Figura 3. A. Tamaños de los fragmentos analizados. B. Espesores máximos y mínimos de las paredes por grupo de fragmentos 


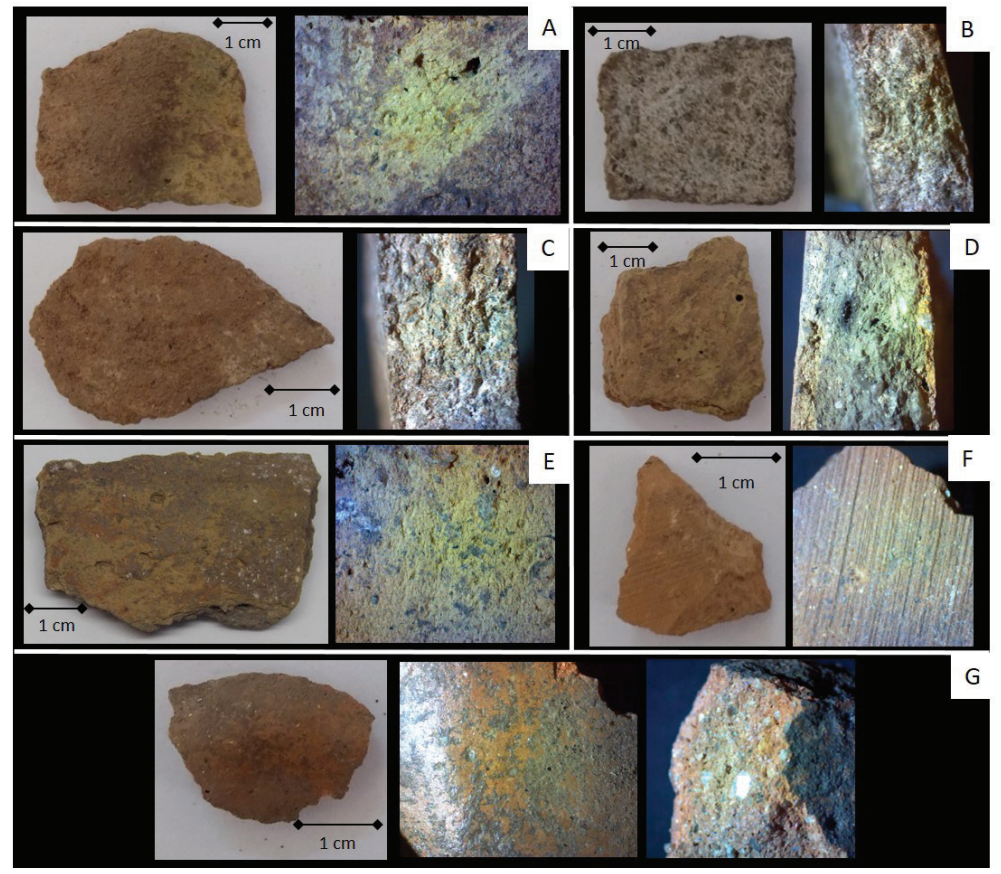

Figura 4. Fragmentos de cerámica procedentes de PNO 1. A. fragmento 5443: pared externa y foto con lupa a 10x. B. Fragmento 6165-B51: pared interna, pared externa y corte longitudinal de pared a 10x.C.

Fragmento 4429: pared externa y corte longitudinal de pared a 10x. D. Fragmento 5427-D24: pared exterior y foto con lupa a 10x de corte longitudinal de pared. E. Fragmento 3510: pared exterior foto con lupa a 10x de pared interior. F. Fragmento 3519: izquierda pared exterior y foto con lupa a 10x de pared exterior. G. Fragmento 2466: pared exterior, foto con lupa a 10x de pared exterior con pulido y corte longitudinal de pared

Luego de establecer este panorama, el conjunto fue separado a través de observación a ojo desnudo de las características más sobresalientes: tratamientos y decoración de las superficies, cocción y, en los casos posibles, evidencias de uso. Se identificaron cinco Grupos que podrían referir a vasijas específicas, mientras que el Grupo 6 reúne diversos tipos de fragmentos sin posibilidad de agruparse con otros (tabla 2). Estos grupos de fragmentos presentan características particulares, las cuales se encuentran detalladas en la tabla 3.

En términos generales, el Grupo $1(n=8)$ se destaca por presentar tratamientos superficiales específicos: en seis fragmentos se observó engobe en la superficie externa. Este consiste en tratar la superficie de la pieza, generalmente antes de la cocción, con un revestimiento de naturaleza arcillosa y posteriormente pulirlo. En este caso, se pudo determinar por su descascarado. Además, en seis casos se observó esta superficie con pulido, mientras que en los otros dos solo fueron alisados. En cambio, para las superficies internas solo se realizó alisado en los ocho fragmentos. Para la inferencia de la atmósfera de cocción, se tomó en cuenta que la totalidad de los fragmentos presentaban una coloración marrón-rojiza, tanto en sus superficies como en el núcleo. Por lo tanto, se infiere una atmósfera oxidante. Respecto a los efectos de uso, en este grupo solo se observó un caso con manchas negras en la superficie externa. Finalmente, en cuanto a los efectos post-depositacionales, en dos casos se identificaron rayas en las superficies, posiblemente debido a raíces. Para este grupo se estimó un espesor promedio en las paredes de los fragmentos de 0,74 $\mathrm{cm}$. Por su parte, el promedio del tamaño de los fragmentos para este grupo fue $2,53 \mathrm{~cm}$. 
Tabla 2. Grupos establecidos en el conjunto general con su distribución por unidad estratigráfica y los fragmentos seleccionados para corte petrográfico. Entre paréntesis se muestra el número de procedencia de la muestra

\begin{tabular}{|c|c|c|c|c|c|}
\hline Grupo & Descripción del grupo & $\begin{array}{c}\text { Distribución } \\
\text { en el } \\
\text { conjunto } \\
\end{array}$ & $\mathbf{N}^{\circ}$ & UE & $\begin{array}{c}\text { Muestra corte } \\
\text { petrográfico }\end{array}$ \\
\hline \multirow[b]{2}{*}{ Grupo 1} & \multirow{2}{*}{$\begin{array}{l}\text { Fragmentos con posibles engobes en las } \\
\text { superficies externas. Las superficies se } \\
\text { encuentran alteradas }\end{array}$} & \multirow[b]{2}{*}{$20 \%$} & 2 & UE5 & 5 (5427-D24) \\
\hline & & & 6 & UE6 & \\
\hline \multirow[b]{2}{*}{ Grupo 2} & \multirow{2}{*}{$\begin{array}{c}\text { Fragmentos de color gris/negro } \\
\text { decorados con técnicas de incisión y/o } \\
\text { estampamiento }\end{array}$} & \multirow[b]{2}{*}{$10 \%$} & 1 & UE30 & \\
\hline & & & 3 & UE31 & 4 (6165-B51) \\
\hline Grupo 3 & $\begin{array}{l}\text { Fragmento con decoración con pintura } \\
\text { roja en la superficie exterior }\end{array}$ & $2 \%$ & 1 & UE17 & 2 (3510-D57) \\
\hline \multirow{2}{*}{ Grupo 4} & \multirow{2}{*}{$\begin{array}{l}\text { Fragmentos sin decoración y manchas de } \\
\text { hollín en la superficie interna o superficie } \\
\text { interna ennegrecida }\end{array}$} & \multirow{2}{*}{$7 \%$} & 1 & RS & $3(4429)$ \\
\hline & & & 2 & UE35 & \\
\hline Grupo 5 & $\begin{array}{l}\text { Fragmento diferenciado por su pasta. } \\
\text { Muy fina y de color anaranjado. Único } \\
\text { dentro del conjunto }\end{array}$ & $3 \%$ & 1 & UE17 & 7 (3519) \\
\hline \multirow{8}{*}{ Grupo 6} & \multirow{8}{*}{ Fragmentos sin decoración } & \multirow{8}{*}{$58 \%$} & 2 & $\mathrm{RS}$ & \\
\hline & & & 5 & UE2 & $6(4271-C 44)$ \\
\hline & & & 1 & UE5 & $1(5443)$ \\
\hline & & & 2 & UE6 & \\
\hline & & & 2 & UE17 & \\
\hline & & & 4 & UE27 & \\
\hline & & & 4 & UE30 & $9(2466)$ \\
\hline & & & 3 & UE35 & $8(4140)$ \\
\hline
\end{tabular}

En cuanto al Grupo 2 ( $\mathrm{n}=4$ ), las superficies fueron alisadas en todos los casos, y las superficies externas fueron decoradas mediante incisión y/o estampamiento con motivos indeterminados ( $\mathrm{n}=3$ ) o líneas cruzadas $(n=1)$. En cuanto a la cocción, las superficies y el núcleo de color gris-negro, permite inferir una atmósfera reductora, aunque sea en algún punto de la cocción. En ningún caso se registraron rastros de uso, mientras que con respecto a los efectos postdepositacionales, en tres se identificaron manchas blancas, posiblemente calcáreas y en uno, improntas de raíces. El promedio del espesor de las paredes fue $0,73 \mathrm{~cm}$, mientras que el tamaño promedio registrado para los fragmentos fue $2,60 \mathrm{~cm}$.

Con respecto al Grupo $3(\mathrm{n}=1)$, el espesor de la pared de este fragmento fue de $1,10 \mathrm{~cm}$ de espesor (figura 3-C) y su tamaño de 4,94 cm de largo. Este fue el único caso en el que se detectó, además del alisado de las superficies externas, la aplicación de una decoración con pintura monocromática con motivos no determinados, característica que lo diferencia del resto del conjunto. La superficie interna también fue alisada. Para la inferencia de la atmósfera de cocción, se observó la coloración marrón-rojiza del fragmento, tanto en sus superficies como en el núcleo y se infiere una atmósfera oxidante. En este caso no se observaron posibles efectos de uso, aunque sí se identificaron manchas blancas, posiblemente calcáreas.

En el caso de los fragmentos del Grupo $4(n=3)$ presentan en su totalidad las superficies alisadas, tanto las externas como las internas, sin ninguna decoración. Con respecto a la atmósfera 
de cocción, se observó variabilidad en los colores, tanto de las superficies como de los núcleos. Dos casos presentan superficies marrón-rojizas y el otro, marrones $(n=1)$. A pesar de esta diferencia se puede inferir una atmósfera oxidante. Para este grupo, se observó hollín en las superficies internas $(n=2)$ y en otro caso $(n=1)$ ennegrecimiento de la superficie interna. En este grupo no se observaron posibles efectos post-depositacionales. Los espesores de las paredes fueron promediados en 0,67 $\mathrm{cm}$, mientras que el tamaño máximo promediado para los fragmentos fue de $2,75 \mathrm{~cm}$.

Respecto al Grupo $5(\mathrm{n}=1)$, conformado por un solo fragmento, presenta las superficies (externa e interna) alisadas con rastros del instrumento utilizado para tal fin, sin ningún tipo de decoración. Para la inferencia de la atmósfera de cocción, se tomó en cuenta el color marón-anaranjado de las superficies y núcleo para inferir una atmósfera oxidante. En este caso no se identificaron evidencias de uso ni de factores postdepositacionales. El espesor del fragmento fue $0,85 \mathrm{~cm}$, mientras que su tamaño registrado fue de $2,34 \mathrm{~cm}$.

Por último, el Grupo $6(\mathrm{n}=23)$ se compone de fragmentos que no han podido asignarse a otros grupos o cuyas diferencias no fueron determinantes para discriminar en un grupo nuevo. Por lo tanto, al ser el más numeroso, presenta mayor variabilidad interna (tabla 3). Un caso presenta inclusiones orgánicas quemadas en la pasta. En este grupo se observó que en catorce fragmentos las superficies externas solo fueron alisadas y en dos se observó un posible pulido, para el resto no se pudo identificar un tratamiento particular en las superficies. Esta diferencia puede deberse a que los fragmentos provengan de distintos sectores de una vasija o a que los procesos ocurridos durante el uso y depositación hayan eliminado estos rastros. Por su parte, la totalidad de los casos presenta la superficie interna alisada. Para la inferencia de la atmósfera de cocción, se observó variabilidad en los colores, entre marrones, rojizos y algunos más grisáceos. Sin embargo, los núcleos y las superficies internas permiten inferir atmósferas de cocción oxidantes.

Para este grupo más numeroso, la mayoría de los fragmentos no presentan evidencias de uso visibles $(n=22)$, pero en un caso se identificaron marcas negras en la superficie interna. Con respecto a los efectos post-depositacionales, en la mayoría de los fragmentos no hay ningún tipo de evidencia $(n=15)$ al respecto. Sin embargo, se observaron fragmentos con manchas blancas en las superficies $(n=3)$, superficie externa blanquecina con impronta de raíces $(n=2)$, rayas en las superficies $(n=2)$ y un fragmento con impronta de raíces. El espesor promedio de las paredes para este grupo es de 0,69 cm y el tamaño promedio de los fragmentos es de 2,66 cm.

\section{Análisis petrográficos}

Las muestras seleccionadas corresponden a fragmentos asignados a los distintos grupos establecidos en el apartado anterior (tabla 2). El análisis de componentes principales sobre las nueve muestras, mostró que el componente 1 (CP 1) representa el 67,368\% de la varianza, mientras que el componente 2 (CP 2), el 12,349\%, lo que conforma el 79,717\% de la varianza total del conjunto. El CP 1 presenta una relación negativa con la variable matriz y positiva con las inclusiones de litoclastos graníticos, mientras el CP 2 muestra relación negativa con la variable moscovita y positiva con el cuarzo.

Por lo tanto, el gráfico de ACP (figura 5) muestra en el cuadrante superior derecho aquellas muestras con cantidades significativas de cuarzo y rocas graníticas $\left(\mathrm{N}^{\circ} 3,4\right.$ y 6). En este sector también se separa un fragmento $\left(\mathrm{N}^{\circ} 8\right)$ que presenta porcentajes apenas mayores de moscovita que los anteriores. Mientras tanto, en el cuadrante inferior derecho se ubica un ejemplar $\left(\mathrm{N}^{\circ} 7\right)$ con altas densidades de moscovita, poca matriz y poco cuarzo. Por su parte, en el lado izquierdo se ubican muestras con menos inclusiones de rocas graníticas y poca moscovita $\left(\mathrm{N}^{\circ} 1,2\right.$ y 5 ). Finalmente, se separa un fragmento, sobre el cuadrante inferior derecho que muestra los porcentajes más altos de matriz de todo el conjunto y pocas cantidades de cuarzo $\left(\mathrm{N}^{\circ} 9\right)$. 


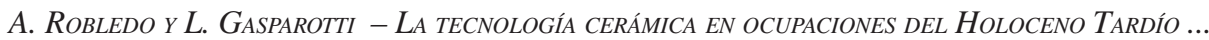

Tabla 3. Descripción de pastas en los diversos grupos a nivel macroscópico/bajos aumentos

\begin{tabular}{|c|c|c|c|c|c|c|c|}
\hline & & Grupo 1 & Grupo 2 & Grupo 3 & Grupo 4 & Grupo 5 & Grupo 6 \\
\hline \multirow{5}{*}{$\begin{array}{c}\text { Inclusiones } \\
\text { no } \\
\text { plásticas }\end{array}$} & Tipo & $\begin{array}{l}\text { Cuarzo, } \\
\text { feldespato, } \\
\text { mica e } \\
\text { inclusiones } \\
\text { orgánicas } \\
\text { quemadas }\end{array}$ & $\begin{array}{c}\text { Micas } \\
\text { (densidades } \\
\text { variables), } \\
\text { cuarzo, } \\
\text { feldespatos, } \\
\text { pegmatitas } \\
\text { y otras } \\
\text { inclusiones } \\
\text { de color } \\
\text { negro o grises }\end{array}$ & $\begin{array}{c}\text { Cuarzos, } \\
\text { feldespatos, } \\
\text { inclusiones } \\
\text { negras } \\
\text { y grises } \\
\text { y pocas } \\
\text { cantidades } \\
\text { de mica }\end{array}$ & $\begin{array}{c}\text { Micas, } \\
\text { cuarzo, } \\
\text { feldespatos, } \\
\text { inclusiones } \\
\text { negras } \\
\text { y grises } \\
\text { (podrían ser } \\
\text { granitos) y } \\
\text { pegmatitas }\end{array}$ & $\begin{array}{c}\text { Micas, } \\
\text { cuarzos y } \\
\text { feldespatos }\end{array}$ & $\begin{array}{c}\text { Micas, } \\
\text { cuarzo, } \\
\text { feldespatos } \\
\text { pegmatitas y } \\
\text { otras de color } \\
\text { negro o gris }\end{array}$ \\
\hline & Densidad & $10 \%$ & 5 a $10 \%$ & $10 \%$ & 20 a $30 \%$ & $5 \%$ & 5 a $30 \%$ \\
\hline & Forma & $\begin{array}{c}\text { sub- } \\
\text { redondeadas }\end{array}$ & $\begin{array}{l}\text { sub-angulares } \\
\text { a sub- } \\
\text { redondeadas }\end{array}$ & $\begin{array}{c}\text { sub- } \\
\text { angulares }\end{array}$ & $\begin{array}{l}\text { sub-angulares } \\
\text { y sub- } \\
\text { redondeadas }\end{array}$ & angulares & $\begin{array}{c}\text { sub-angulares } \\
\text { y sub- } \\
\text { redondeadas }\end{array}$ \\
\hline & $\begin{array}{l}\text { Tamaños } \\
(\mathbf{m m})\end{array}$ & $0,5-3,0$ & $0,5-3,0$ & $0,5-3,0$ & $0,5-3$ & 0,5 & $0,5-3,0$ \\
\hline & Distribución & $\begin{array}{c}\text { muy pobre } 0 \\
\text { pobre }\end{array}$ & pobre & pobre & pobre & muy pobre & $\begin{array}{c}\text { pobre a muy } \\
\text { pobre }\end{array}$ \\
\hline \multirow{4}{*}{ Cavidades } & Densidad & $\begin{array}{l}\text { entre } 10 \% \\
\text { y } 5 \%\end{array}$ & $\begin{array}{c}\text { entre } 10 \% \\
\text { y } 5 \%\end{array}$ & $10 \%$ & $\begin{array}{c}\text { entre } 10 \% \\
\text { y } 5 \%\end{array}$ & $5 \%$ & 5 al $10 \%$ \\
\hline & Formas & indefinidas & indefinidas & indefinidas & indefinidas & indefinidas & indefinidas \\
\hline & $\begin{array}{c}\text { Tamaño } \\
(\mathbf{m m})\end{array}$ & $0,25-0,5$ & $0,5-1$ & $0,25-0,5$ & $0,25-1$ & hasta 0,1 & $0,25-0,5$ \\
\hline & Distribución & muy pobre & muy pobre & muy pobre & muy pobre & muy pobre & Muy pobre \\
\hline \multicolumn{2}{|c|}{$\begin{array}{l}\text { Tamaño promedio de los } \\
\text { fragmentos }(\mathrm{cm})\end{array}$} & 2,53 & 2,60 & 4,94 & 2,75 & 2,34 & 2,66 \\
\hline \multicolumn{2}{|c|}{$\begin{array}{c}\text { Espesor promedio de las } \\
\text { paredes }(\mathrm{cm})\end{array}$} & 0,74 & 0,73 & 1,18 & 0,67 & 0,85 & 0,68 \\
\hline
\end{tabular}

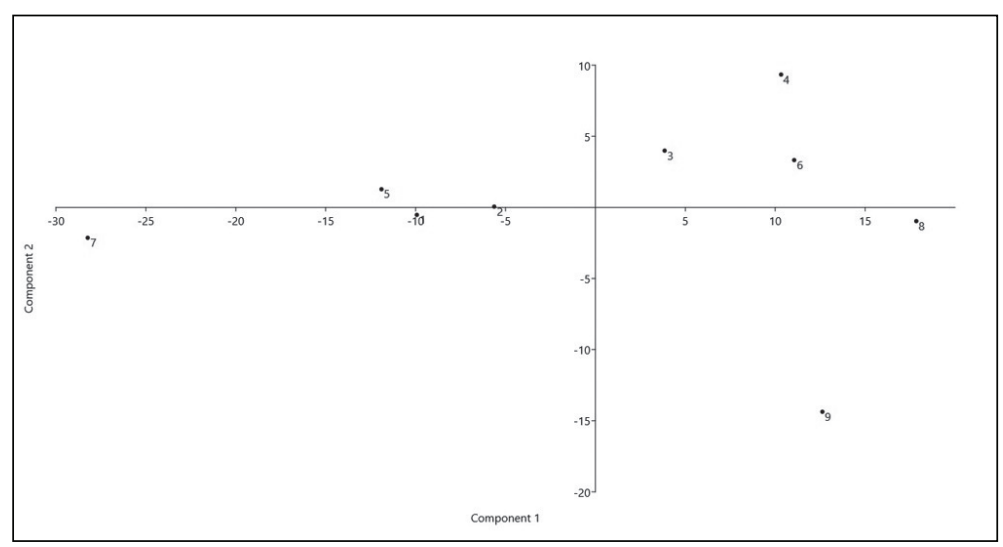

Figura 5. Gráfico de Análisis de Componentes Principales 
Posteriormente se aplicó un análisis de conglomerado jerárquico con el método de pares agrupados, obteniendo un conglomerado con un coeficiente cofenético de 0,7107 (figura 6). De este análisis se desprende la separación de cuatro tipos petrográficos (figura 7). Estos tipos pudieron caracterizarse, en primera instancia, según la abundancia de los tres componentes analizados (matriz, cavidades e inclusiones), lo cual arrojó la existencia de pastas finas, intermedias y gruesas. Solo una muestra fue catalogada como pasta fina $\left(\mathrm{N}^{\circ} 7\right)$ que presenta porcentajes de pastas cercanos al 75\%, mientras que las inclusiones no plásticas se registraron en porcentajes cercanos al $15 \%$. Las pastas intermedias $(n=3)$ presenta una densidad de inclusiones que puede variar entre el 36 al 44\%, mientras que la matriz fue estimada en porcentajes que van desde el $52 \%$ hasta el $60 \%$. Finalmente, las pastas gruesas $(n=5)$ se caracterizan por presentar densidades de matriz entre 33 y 50\%, mientras que los porcentajes de inclusiones no plásticas varían entre $47 \%$ y $58 \%$ (figura 6). Esta división es meramente descriptiva, por lo que se profundizó en el establecimiento de Tipos Petrográficos (tabla 4), los cuales se diferencian en función de las características composicionales de las pastas, lo cual incluye la naturaleza de las inclusiones. A continuación, se detallan los tipos petrográficos.

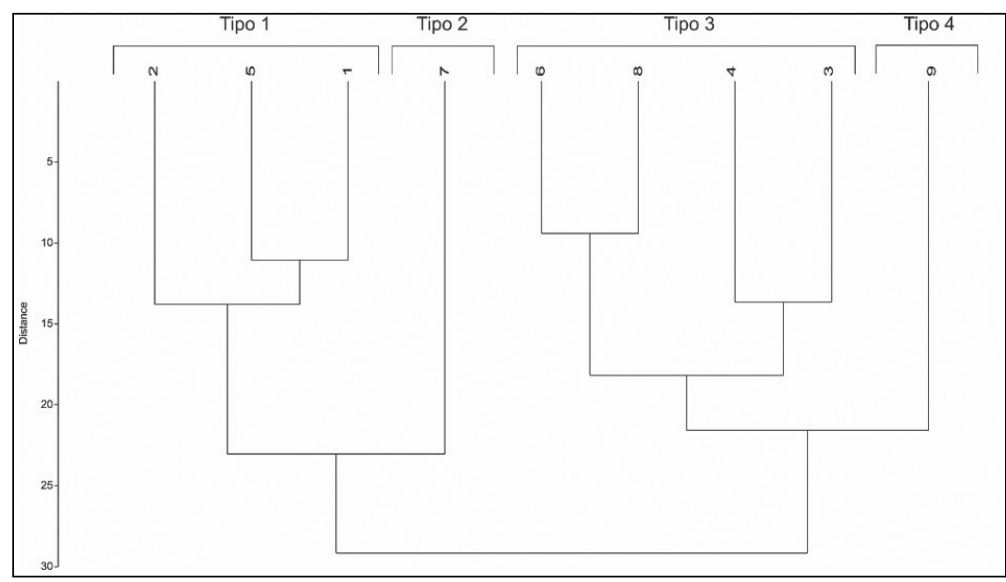

Figura 6. Conglomerado estadístico

\section{Pastas finas}

La única muestra asignada como pasta fina está catalogada como tipo petrográfico 2 y corresponde a la muestra 7 , la cual presenta los porcentajes más elevados de matriz de todo el conjunto $(74,87 \%)$. Las cavidades rondan el $9,5 \%$. Por su parte, las inclusiones no plásticas se componen por cuarzo $(5,276 \%)$, con las densidades más bajas de todo el conjunto, plagioclasa en muy bajas cantidades $(1 \%)$, microclinos $(1,25 \%)$, plagioclasas alteradas $(1,5 \%)$, biotitas $(0,25 \%)$, moscovitas $(2,76 \%)$, porixenos $(0,5 \%)$, litoclastos graníticos $(1,25 \%)$ y litoclastos volcánicos $(0,503 \%)$. Esta muestra se diferencia del resto, además, por presentar inclusiones de gránulos de arcilla (1,25\%), posiblemente relacionadas con un amasado u homogeneización pobre de la arcilla. Los tamaños promedios de las inclusiones no plásticas se ubican en torno a los 0,39 mm. Las formas observadas son muy variables, pudiéndose encontrar inclusiones angulares, sub-angulares, sub-redondeadas y redondeadas, además de las micas que se presentan de forma laminar. El tamaño promedio de las cavidades en esta muestra es de $0,34 \mathrm{~mm}$. Las formas observadas fueron sub-redondeadas o amorfas. 


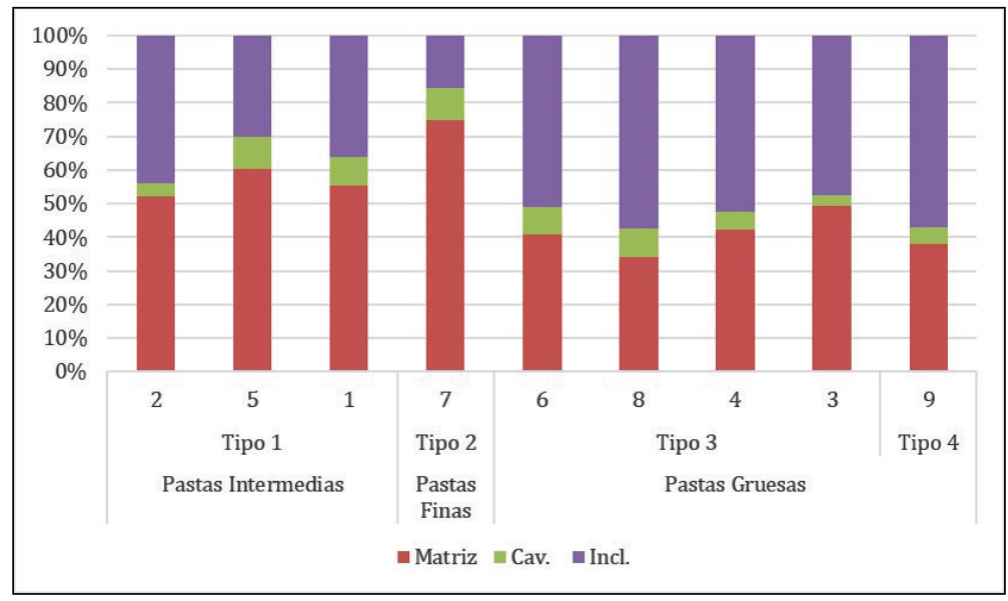

Figura 7. Grupos de pasta según la abundancia de matriz e inclusiones no plásticas

\section{Pastas intermedias}

Estas pastas están directamente relacionadas con el tipo petrográfico 1, que engloba tres muestras. En detalle, este tipo presenta porcentajes de matriz que varían entre $52 \%$ y $60 \%$. Las cavidades o poros se contabilizan en densidades entre 3,92\% y 9,43\%. Las inclusiones no plásticas se caracterizan por la presencia de cuarzo (entre 11,8 y 14\%), plagioclasas (entre 4,45 y 7,23\%), plagioclasas alteradas a sericita (entre $2 \%$ y $6,6 \%$ ), litoclastos graníticos (entre 0,636 y 2,516\%). También se registraron micas, microclino y algunos minerales opacos. Uno de los rasgos más llamativos es la presencia de litoclastos volcánicos en las tres muestras, que se asocian a dacitas/ andesitas, aunque resalta la muestra 2 por contabilizar un 10,54\% de litoclastos volcánicos. Los tamaños de las inclusiones no plásticas presentan un promedio de 0,42 $\mathrm{mm}$. En este conjunto se observa la mayor variabilidad en los tamaños y la muestra $\mathrm{N}^{\circ} 1$ es que tiene mayor diferenciación entre los tamaños máximo y mínimo registrado.

Dentro de este conjunto, la muestra $\mathrm{N}^{\circ} 5$ presenta los tamaños mínimo y máximo más próximos entre sí, lo que indica, tal vez, una distribución unimodal de las inclusiones de tamaños pequeños. Esta muestra presenta los valores máximos más pequeños de todo el conjunto analizado. Las formas de las inclusiones varían entre sub-angular, sub-redondeada y redondeadas, con excepción de las micas, que siempre se presentan de forma laminar. El tamaño promedio de las cavidades es de $0,77 \mathrm{~mm}$. Las formas de las cavidades son alargadas o vesiculares.

Este conjunto de pastas, junto con el Tipo 2, se distingue del resto justamente por contener inclusiones de litaclastos volcánicos y poca densidad de fragmentos de rocas graníticas.

Tabla 4. Características cuantitativas de cada tipo petrográfico

\begin{tabular}{|c|c|c|c|c|c|c|c|c|c|}
\hline Tipo & & 1 & & 2 & & & & & 4 \\
\hline Muestra & 2 & 5 & 1 & 7 & 6 & 8 & 4 & 3 & 9 \\
\hline Matriz & 52,206 & 60,377 & 55,297 & 74,874 & 40,988 & 33,92 & 42,149 & 49,315 & 38,024 \\
\hline Cavidades & 3,922 & 9,434 & 8,475 & 9,548 & 7,849 & 8,794 & 5,51 & 3,014 & 5,09 \\
\hline Cuarzo & 13,235 & 13,836 & 11,864 & 5,276 & 16,279 & 17,085 & 29,477 & 21,096 & 13,473 \\
\hline Plagioclasa & 5,882 & 7,233 & 4,449 & 1,005 & 4,942 & 10,05 & 7,163 & 12,055 & 17,665 \\
\hline
\end{tabular}


Relaciones de la Sociedad Argentina de Antropología 46 (1), enero-junio 2021: 177-203

(Tabla 4. Continuación)

\begin{tabular}{|c|c|c|c|c|c|c|c|c|c|}
\hline Tipo & \multicolumn{3}{|c|}{$\mathbf{1}$} & $\mathbf{2}$ & \multicolumn{3}{|c|}{$\mathbf{3}$} & $\mathbf{4}$ \\
\hline Microlino & 0,98 & 0,943 & 1,907 & 1,256 & 0,872 & 0,754 & 1,102 & 2,466 & 1,198 \\
\hline $\begin{array}{c}\text { Plag. } \\
\text { Alterada }\end{array}$ & 6,618 & 3,459 & 1,695 & 1,508 & 6,977 & 7,035 & 4,959 & 0,822 & 2,395 \\
\hline Sericita & 0 & 0 & 6,356 & 0 & 0 & 0 & 0 & 0 & 0 \\
\hline Biotita & 0,245 & 0,314 & 0,212 & 0,251 & 0,872 & 0,754 & 0 & 0 & 0,898 \\
\hline Moscovita & 1,225 & 0 & 0,636 & 2,764 & 2,616 & 5,025 & 1,102 & 0,274 & 14,97 \\
\hline Feldespato & 0 & 0 & 0,636 & 0 & 0 & 0 & 0 & 0 & 0 \\
\hline Piroxeno & 0 & 0 & 0 & 0,503 & 0 & 0 & 0,275 & 0 & 0 \\
\hline $\begin{array}{c}\text { Min. } \\
\text { Opacos }\end{array}$ & 0,49 & 0 & 0 & 0 & 0 & 0 & 0,551 & 0 & 0 \\
\hline $\begin{array}{c}\text { Rocas } \\
\text { Granit. }\end{array}$ & 1,716 & 2,516 & 0,636 & 1,256 & 18,605 & 16,332 & 7,163 & 10,959 & 6,287 \\
\hline $\begin{array}{c}\text { R. G. } \\
\text { Alteradas }\end{array}$ & 2,941 & 0 & 5,932 & 0 & 0 & 0 & 0 & 0 & 0 \\
\hline $\begin{array}{c}\text { Lit. } \\
\text { Volcánico } \\
\text { (Da/And) }\end{array}$ & 10,539 & 1,887 & 1,907 & 0,503 & 0 & 0 & 0,551 & 0 & 0 \\
\hline $\begin{array}{c}\text { Grano } \\
\text { Arcilla }\end{array}$ & 0 & 0 & 0 & 1,256 & 0 & 0 & 0 & 0 & 0 \\
\hline $\begin{array}{c}\text { Tiesto } \\
\text { Molido }\end{array}$ & 0 & 0 & 0 & 0 & 0 & 0,251 & 0 & 0 & 0 \\
\hline
\end{tabular}

\section{Pastas gruesas}

Dentro de estas pastas, se encuentran los tipos petrográficos 3 y 4 con un total de cinco muestras. Estas pastas presentan los porcentajes más elevados de cuarzo de todo el conjunto analizado, sumado a la mayor presencia de fragmentos de rocas graníticas, a diferencia del resto de los tipos englobados en pastas finas e intermedias.

El tipo petrográfico $3(\mathrm{n}=4)$ presenta densidades de matriz que varían entre $34 \%$ y 49,3\%, mientras que las cavidades fueron registradas en porcentajes entre 3 y $8,7 \%$. Las inclusiones no plásticas se caracterizan por presentar cuarzo (entre 16,28\% y 29,48\%) en las proporciones más elevadas de todo el conjunto analizado, plagioclasas (entre $4,92 \%$ y $12 \%$ ), plagioclasas alteradas (entre 7 y $0,82 \%$ ), microclinos (entre 0,75 y $2,466 \%$ ), micas en cantidades variables. La variable que presenta mayor diferenciación es la presencia de rocas o litoclastos de origen granítico, ya que son las más elevadas de todo el conjunto (entre $1,6 \%$ y $7,16 \%$ ). Solo la muestra $\mathrm{N}^{\circ} 8$ se diferencia por presentar inclusiones de tiesto molido, aunque en densidades poco apreciables, por lo que el análisis estadístico la agrupó en conjunto con otras muestras. El tamaño promedio de las inclusiones no plásticas es de 0,66 mm. Las formas observadas varían entre sub-angulares a sub-redondeadas, con excepción de las micas, que siempre se presentan de forma laminar. Por su parte, el tamaño promedio de las cavidades es de $0,54 \mathrm{~mm}$. Las formas registradas son variables, pudiéndose encontrar cavidades amorfas o vesiculares.

Finalmente, el tipo petrográfico 4 se compone por una sola muestra. Este tipo presenta densidades bajas de matriz (38\%) y también de cavidades o poros $(5,09 \%)$. Las inclusiones no plásticas están conformadas por plagioclasas como mineral dominante, con las densidades más 
altas de todo el conjunto $(17,66 \%)$, cuarzo $(13,47 \%)$, microclino $(1,2 \%)$, plagioclasas alteradas $(2,39 \%)$ y biotita $(0,89 \%)$. El rasgo distintivo, además de la presencia de altas cantidades de plagioclasas, es la contabilización de importantes cantidades de moscovita $(14,97 \%)$, lo cual la diferencia del tipo petrográfico 3. También se registraron litoclastos graníticos en cantidades considerables (6,29\%). El tamaño promedio de las inclusiones no plásticas de esta muestra es de 0,41 $\mathrm{mm}$. Las formas registradas varían de sub-angular a angular, mientras que las micas siempre se presentan en forma laminar. El tamaño promedio de las cavidades en esta muestra es de 0,288. Las formas registradas fueron sub angulares.

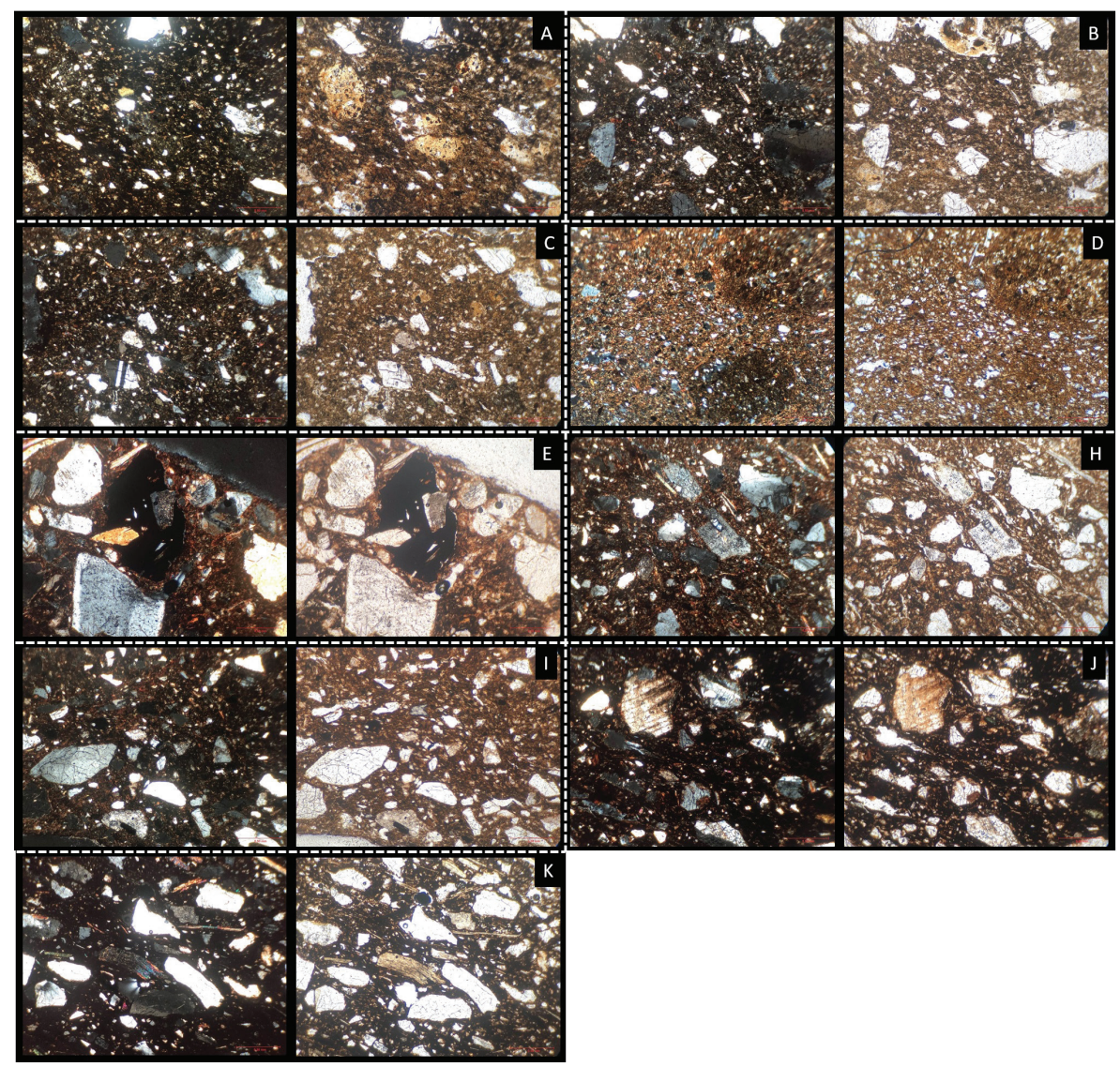

Figura 8. Fotografía de los tipos petrográficos (izquierda luz polarizada, derecha luz paralela). Tipo petrográfico 1: A. muestra $\mathrm{N}^{\circ} 2$; $\mathrm{B}$. muestra $\mathrm{N}^{\circ}$ 5; C. muestra $\mathrm{N}^{\circ} 1$; Tipo petrográfico 2: D. muestra $\mathrm{N}^{\circ}$ 7; Tipo petrográfico 3: E. muestra $\mathrm{N}^{\circ} 8$; H. muestra $\mathrm{N}^{\circ}$ 6; I. muestra $\mathrm{N}^{\circ} 4$; J. muestra $\mathrm{N}^{\circ}$ 3; Tipo petrográfico 4: K. muestra $\mathrm{N}^{\circ} 9$

\section{DISCUSIÓN}

Las investigaciones que se llevan a cabo en PNO 1 permiten aportar a la comprensión de las prácticas y la vida cotidiana de las personas que habitaron el valle de Ongamira durante una larga secuencia del Holoceno (Cattáneo e Izeta 2016). Nuestro trabajo es una contribución inicial a una problemática que continúa teniendo interrogantes para las distintas regiones de las Sierras Pampeanas Australes. Por lo tanto, el estudio de la alfarería procedente de los contextos 
estratigráficos de PNO 1 permite brindar elementos para conocer las prácticas de la elaboración, uso y descarte de una materialidad que pudo haber incorporado grandes cambios en la vida de las personas. Particularmente, nos enfocamos en un período entre $c a$. 650 años y $c a$. 1900 años AP, considerando los fechados más tardíos hasta el momento para el valle de Ongamira (Cattáneo et al. 2019). Somos conscientes que la muestra abordada aún es reducida, sin embargo, creemos que es un primer acercamiento para la comprensión del contexto específico de PNO 1. Además, esperamos a futuro poder ampliar las excavaciones en el sitio a los fines de aumentar el número de análisis realizados y aportar mayor información contextual para las ocupaciones asociadas al Holoceno Tardío.

Con esto en cuenta, y retomando los resultados, el material cerámico recuperado permitió identificar al menos seis grupos de fragmentos discriminados por sus características macroscópicas que, por sus dimensiones y estado de conservación, no permiten asignar formas o tamaños completos de artefactos cerámicos. Sin embargo, sí podemos plantear la existencia de, al menos, seis vasijas en PNO 1 que fueron descartadas en distintos momento y sectores del alero.

A pesar del estado fragmentario de la muestra y de que representa una menor proporción con relación al resto de las materialidades (e.g. 3.000 restos faunísticos, 800 fragmentos de material lítico y 5.000 fragmentos de carbón) recuperadas en las áreas excavadas (Robledo et al. 2018; Robledo 2020), la presencia de cerámica en el sitio resulta de interés para resaltar algunos puntos donde se pueden interpretar posibles usos o formas de habitar el alero de acuerdo a las actividades realizadas. A raíz de esto, ordenaremos la discusión de los resultados en dos ejes: primero abordamos la relación distribucional de los hallazgos de cerámica en vínculo con las unidades estratigráficas y sus relaciones con las actividades llevadas a cabo en el sitio. Luego, observamos las características tecnológicas observadas en el conjunto cerámico recuperado, haciendo énfasis en los datos obtenidos de la petrografía de pastas y las implicancias sobre la obtención de materias primas y la producción.

\section{La alfarería en la matriz}

A partir de los registros realizados durante las excavaciones y la posibilidad de reconstruir la historia de los eventos ocurridos en PNO 1 (matriz de Harris), nos es posible indagar en la relación de estos eventos con la presencia de esta materialidad en particular. En primer lugar, observamos que existe una distribución diferenciada de los fragmentos dentro de la superficie excavada del sitio (tabla 2), donde en la mayoría de los casos se han registrados dos o más Grupos por unidad estratigráfica. Con la excepción que podemos encontrar en la UE27 (figura 1) donde solo se registraron fragmentos del Grupo $6(n=4)$ y en la UE31, descripta como un lente de ceniza, con fragmentos del Grupo $2(\mathrm{n}=3)$.

Al respecto de esta última (UE31), similar a lo descrito por González y Menghin para ADR (1954:121), se recuperaron fragmentos decorados mediante incisión y estampamiento con motivos indeterminados, uno de ellos con un posible borde. Esto, junto a otro fragmento decorado con líneas cruzadas procedente de la UE30 (unidad estratigráfica que contiene al lente de ceniza UE31) sugiere una relación entre la presencia de estos fragmentos decorados con un momento en que el alero fue habitado y el uso del fuego también estuvo involucrado. Con relación a esto, se ha identificado una mayor presencia de lentes de ceniza asociados a las ocupaciones ca. $1900 \mathrm{y}$ posteriores (Robledo 2020:588), que podría estar relacionado también a la utilización del fuego para actividades de cocción de alimentos o preparación de otras materias primas de origen vegetal, entre otras. La presencia de cenizas refiere a estructuras de combustión que fueron encendidas y dejadas consumir, lo que sugiere la utilización de fogatas por un período de tiempo prolongado. Si bien esto es posible, también debemos considerar otras posibilidades como el descarte de los fragmentos en las fogatas o en sus remanentes ya apagados. 
En otro sector del alero (cuadrícula 1) la UE6 es un rasgo más compactado y con posibles evidencias de termoalteración contenido en la UE5. En ambas se recuperaron fragmentos pertenecientes al Grupo 1; así como también fragmentos del Grupo 6. Estos se encuentran asociados a otras actividades registradas en estas unidades, donde se infirió la manufactura de instrumentos líticos en sus estadios finales junto a remanentes de actividades de combustión asociados al procesamiento y consumo de fauna de especies animales de gran porte como cérvidos y guanacos, así como también una concentración de restos de moluscos asociados a los contextos de combustión y descarte de alimentos (Robledo et al. 2018).

Continuando en el mismo sector, la UE17 fue descripta como un área de combustión (ver tabla 2) con la presencia de restos faunísticos, lascas de cuarzo y fragmentos cerámicos, que en este caso pertenecen a los Grupos 3 y 5 . El primero es el único caso donde se registró una decoración con pintura monocromática rojiza, en tanto el segundo se diferencia por su pasta de color anaranjado y de grosor muy fino. En esta oportunidad se destaca la presencia de dos fragmentos únicos en todo el conjunto que podrían haber sido descartados en los restos de un fogón. Además, podemos mencionar que las decoraciones en rojizo como la del Grupo 3 han sido registradas en otros sitios de las Sierras Pampeanas (Medina 2006; Dantas y Figueroa 2008; Traktman et al. 2020). Estudios a futuro sobre este tipo de vasijas nos podrán referir a intercambio de ideas, formas de hacer y contextos de uso.

Es interesante remarcar que se identificaron fragmentos con marcas de hollín en ambas superficies (Grupo 4) procedentes de la UE35 (Cuadrícula 2) y de recolección superficial. En el caso de los primeros, proceden de la unidad estratigráfica caracterizada por registrar una mayor cantidad de actividades y de material arqueológico, que además pudo ser datada en una antigüedad de $1905+/-20{ }^{14} \mathrm{C}$ años AP (YU-7746, carbón, Izeta et al. 2021). Esto permite proponer para la región serrana una antigüedad mayor a la planteada hasta el momento $c a$. 1500 años a partir de los trabajos de Pastor (2006) en el sitio Río Yuspe 11 y Medina et al. (2016) en el sitio Boyo Paso 2.

Además, podemos señalar que los fragmentos del Grupo 6 fueron separados por no poder ser asignados a otros grupos bien definidos debido a no tener características diferenciables entre sí a nivel macroscópico. No obstante, el grupo no es homogéneo y futuros estudios nos permitirán avanzar en su caracterización y así poder distinguir más tipos de vasijas. De momento, resulta interesante mencionar la presencia de estos fragmentos en siete de las ocho unidades estratigráficas mencionadas anteriormente, lo que podría sugerir además la presencia de diferentes vasijas a la hora de habitar el alero.

En términos generales, podemos mencionar que en PNO 1 se habrían realizado múltiples actividades entre las cuales se destaca la realización de fogatas para las actividades de cocción de alimentos, que además podrían haber actuado como marcadores espaciales internos del alero y en torno a los cuales se realizaron diversas tareas asociadas al procesamiento y consumo de alimentos, la manufactura de instrumentos, entre otros. Esto, aunque aún restan hacer análisis en mayor profundidad, nos aporta mayor información para comenzar a entender las ocupaciones en PNO 1 para estos contextos.

Si partimos de las actividades a las cuales la cerámica estuvo asociada, podemos decir que su uso estuvo en estrecha relación con la cocción o el almacenamiento de frutos y/o líquidos. Además, aunque no hemos podido conocer si el equipo cerámico era transportable o no, sí podemos mencionar que las personas habitaron distintos lugares del valle para realizar diferentes actividades, donde PNO 1 funcionó como un lugar dentro de una red de lugares interconectados por las prácticas, las materialidades y las personas (Robledo 2020:637). Un argumento relacionado ya ha sido indicado para Copacabana por Laguens (1999), quien propone la realización de alfarería en forma expeditiva con el objetivo de cubrir necesidades inmediatas para las ocupaciones del valle. Estudios en profundidad en otros sitios del valle nos permitirán desarrollar esta hipótesis en mayor profundidad. 


\section{La alfarería desde las elecciones tecnológicas}

Por otra parte, en cuanto a la reconstrucción de las elecciones tecnológicas, la información obtenida en los análisis petrográficos nos permite, en primera instancia, poner a prueba la separación macroscópica realizada previamente. Como se puede observar en la figura 9, los tipos petrográficos observados no se corresponden directamente con un solo grupo de fragmentos. Con excepción del Tipo petrográfico 2, que se asocia exclusivamente con el Grupo 5 y el Tipo petrográfico 4 presente solo en el Grupo 6, el resto de los tipos petrográficos se registran en los diversos grupos establecidos macroscópicamente. Esto podría explicarse a través de la utilización de pastas muy similares macroscópicamente, aunque con diferencias solo observables a nivel microscópico.

Además, pudimos observar cómo existieron formas diferentes de preparar las arcillas, lo cual podría estar relacionado a recetas diferentes, fuentes de aprovisionamiento distintas o incluso con alfareros con diversas tradiciones. Si bien esperamos realizar estudios a futuro en una muestra más amplia que nos permita profundizar estas hipótesis, resulta interesante observar que, ante preparados de pastas similares, las terminaciones en algunos casos fueron diferentes. Por ejemplo, entre las pastas gruesas encontramos fragmentos del Grupo 4 que podrían ser diferentes a los del Grupo 2 (decorados) procedentes de distintos sectores del alero. En este caso, aunque no podemos descartar la posibilidad de que sean partes del mismo artefacto, preparados de pastas similares podrían haber tenido finalidades diferentes.

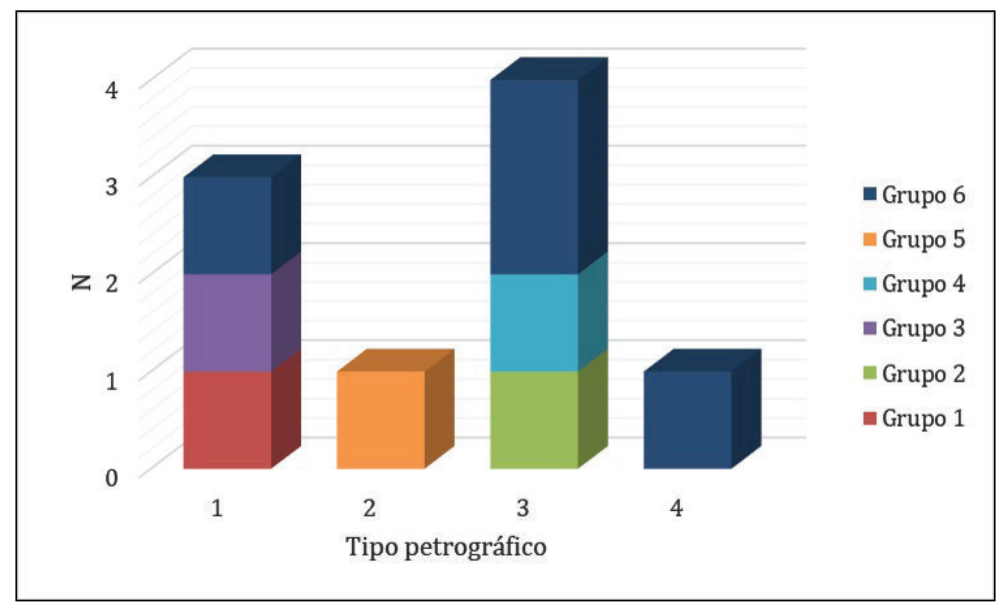

Figura 9. Distribución de los Grupos de fragmentos por tipo petrográfico

En la misma línea, dentro de las pastas gruesas y del Grupo 6, uno de los fragmentos (muestra 8) perteneciente a la UE35 tiene tiesto molido en bajos porcentajes dentro de la composición de su pasta. Esta característica resulta relevante ya que es el único caso en el conjunto estudiado por nosotros y solo contamos con otro registrado hasta el momento para el valle de Copacabana (Traktman et al. 2020), sin embargo, en el caso de PNO 1 su inclusión en la pasta puede ser accidental, debido a su baja significancia. La presencia de tiesto molido en las pastas todavía necesita del estudio de una muestra más amplia, en especial si consideramos que el registro de estos casos para las Sierras Pampeanas Australes ha sido escaso. La toma de decisiones asociada a la reutilización de restos de vasijas anteriores para el armado de nuevas podría tener diferentes significaciones de acuerdo a los contextos de producción y de uso para cada caso, esperamos avanzar en la caracterización de estos contextos a futuro para el valle de Ongamira. 
En el caso de las pastas finas e intermedias vemos que existe una mayor variabilidad en el acabado y decoración, donde cada corte petrográfico estudiado pertenece a Grupos de fragmentos diferentes (figura 9).

Como mencionamos anteriormente, la caracterización composicional de pastas permite aproximarnos a la procedencia de las materias primas. Por lo tanto, retomar las características de la geología local resulta de suma relevancia para esbozar algunas hipótesis. De acuerdo a esto, en base a la Hoja Geológica 3163-I Jesús María (Candini et al. 2001:40), se puede afirmar que PNO 1 se encuentra dispuesto sobre el terreno que corresponde al Conglomerado Los Terrones y la Formación Saldán (figura 1).

A esto, debemos sumar al Complejo Ígneo Sierra Norte donde destacamos la existencia de conspicuos cuerpos y diques subvolcánicos, localizados más al norte del valle, de naturaleza riolítica, dacítica, mesosilícica y lamprofírica. Estos intruyen las principales litologías que constituyen el batolito de Sierra Norte. Estas manifestaciones están representadas en las ignimbritas La Lidia, ubicadas a unos $60 \mathrm{~km}$ al noroeste de nuestro sitio de estudio, sobre la Sierra Sauce Puncu. Se trata de tobas, ignimbritas riolíticas y mantos riolíticos (Lira y Poklepovic 2014). Este componente geológico es importante en el contexto de análisis ya que introduce variabilidad en la geología regional.

También hay registros de varias fuentes de arcilla en la región, las cuales podrían haber servido como fuentes de aprovisionamiento de materia prima tanto para los pobladores del valle de Ongamira como también las ocupaciones registradas en el valle de Copacabana (Laguens 1999; Bertolino et al. 2010; Traktman et al. 2020) y alrededores. Aunque todavía es necesario realizar estudios específicos en cada uno de ellos, podemos mencionar el Yacimiento El Reposo localizado en el valle a $200 \mathrm{~m}$ del sitio (figura 1), el cual se describe como un depósito de arcilla roja, friable y plástica con minerales predominantes como esmectitas con illita, clorita, caolinita y cuarzo subordinados (Alonso y Gaido 2018:7). Además, se pueden mencionar el yacimiento Las Higueritas, localizado en las cercanías del valle de Copacabana y Puesto Viejo, 6 km al este del valle de Ongamira.

Al poner en este contexto los resultados obtenidos en los análisis petrográficos, se pudieron establecer dos tipos de composición claros en las pastas cerámicas. Existe un grupo de pastas con inclusiones de origen volcánico (Tipos petrográfico 1 y 2) y otro conjunto con una alta proporción de rocas de origen granítico (Tipos petrográficos 3 y 4). En conjunto, esta información, sumada a los datos geológicos existentes, nos permiten proponer que aquellas pastas agrupadas en los Tipos 3 y 4 fueran elaboradas a partir de materias primas inmediatamente locales. Mientras tanto, dada la presencia de inclusiones de origen volcánico (andesitas o dacitas), posiblemente la localización de estas materias primas pueda estar más al norte y relacionarse con la formación la Lidia. Esto podría hacer referencia a la existencia de otro modo de preparar las pastas, partiendo de materias primas que no estarían disponibles localmente y elecciones tecnológicas diferentes. Una situación similar también ha sido registrada por Traktman y colaboradores (2020). Por el contrario, en los análisis llevados a cabo por Carosio et al. (2021) no se registraron este tipo de variaciones en las materias primas debido a la homogeneidad geológica de la región. Aquí podemos notar una diferencia remarcable entre estos conjuntos cerámicos. Podríamos decir que, las cerámicas de PNO 1 comparten más características con aquellas de Copacabana que con las del valle de Punilla, Salsacate o Pampa de Olaen. Esta propuesta, sin embargo, debe seguir estudiándose en profundidad, sumando más material a los análisis.

Por otro lado, el origen local de las vasijas es algo que todavía necesita ser estudiado en mayor profundidad. Menghin y González (1954), en su momento, no acompañaban esta idea fundamentados en que los tipos cerámicos definidos (e.g. Olaen monocroma, San Roque estriada, San Roque tosca, entre otros) estaban asociados a la circulación de objetos por distintas regiones de las sierras de Córdoba y zonas aledañas. Sí habían descrito tiestos con grabados e improntas 
de molde de cesterías cuyos orígenes (locales o foráneos) será necesario profundizar (Menghin y González 1954:1219). En este sentido, nuestro trabajo conforma uno de los primeros aportes que se realizan para el valle de Ongamira sobre cerámica procedente de excavaciones estratigráficas controladas que permitió la descripción macroscópica y petrográfica. Esperamos a futuro ampliar nuestras investigaciones hacia otras áreas del valle y contrastar la información existente con lo estudiado para otras regiones de estudio.

\section{COMENTARIOS FINALES}

Como planteamos en un comienzo, este trabajo tuvo como objetivo caracterizar el conjunto cerámico recuperado de PNO 1 para indagar en las elecciones tecnológicas relacionadas con la manufactura, las condiciones de uso y descarte hacia los $c a$. 1900 años AP y momentos posteriores. En términos generales, se propone que se utilizaron al menos seis vasijas en diferentes contextos de ocupación, las cuales fueron elaboradas de diferentes formas, tanto en sus pastas como en los acabados superficiales y decoraciones. A partir del estudio llevado a cabo, pudimos complejizar las ideas que se tenían hasta el momento de la presencia de la cerámica para el valle de Ongamira.

De los grupos de fragmentos registrados se desprende una mayor variabilidad cuando observamos las características de las pastas. Por un lado, a partir de la petrografía se han identificado cuatro tipos petrográficos, dos de los cuáles contienen inclusiones de origen volcánico probablemente procedente de otras áreas, mientras que otros dos tienen inclusiones que podrían ser de origen local. Esto se diversifica cuando buscamos relacionar los tipos de pastas con los grupos de fragmentos, dado que no observamos que haya una correlación directa. Por el contrario, algunas veces una misma pasta ha sido utilizada para vasijas diferentes. Además, a partir de los estudios petrográficos pudimos registrar una semejanza con los datos obtenidos por Traktman y colaboradores (2020), especialmente en lo relacionado a la elección de dos tipos diferenciados de materias primas para la confección de las vasijas. Esto podría indicar la existencia de elecciones tecnológicas compartidas por los alfareros de la región y al mismo tiempo la circulación de ideas e incluso de objetos entre los valles; algo diferente a lo registrado para el valle de Punilla, Salsacate y Pampa de Olaen (Carosio et al. 2021). Esto podría ser reflejo de diferentes redes de intercambio y redes de circulación de los grupos humanos que esperamos profundizar con futuros estudios.

Varios autores han postulado que la tecnología cerámica para distintas zonas de las Sierras Pampeanas Australes ha sido de uso para actividades domésticas, incluyendo la preservación, preparado o traslado de alimentos y líquidos (Laguens 1999; Dantas y Figueroa 2008; Medina 2008; entre otros). En nuestro caso, aun cuando restan estudios por realizar, podemos destacar la recurrencia de esta materialidad en los diferentes contextos de uso y descarte para las distintas veces en que PNO 1 fue habitado, cuando las personas realizaron diferentes actividades cotidianas relacionadas entre sí tales como el procesamiento de alimentos, la manufactura de instrumentos y el uso del fuego (Costa et al. 2017).

Hasta el momento, queda pendiente profundizar en estos aspectos, así como también sobre los cambios en las formas de procesamiento de los alimentos que posiblemente luego fueron cocinados en las vasijas presentadas en este trabajo. En ese sentido, se ha registrado un aumento en la utilización de leña para las fogatas de especies leñosas con frutos comestibles (e.g. Prosopis sp, Geoffroea sp, Celtis sp., entre otros) (Robledo 2020). Esto podría tener múltiples significaciones, pero nos acerca a la idea de que las personas que habitaron el alero en estos momentos habrían considerado un cambio en la selección de leñas asociada a especies que empezaron a participar en distintos momentos de la vida de las personas. Investigaciones a futuro podrían permitirnos 
avanzar en evidencias de la conservación y consumo de frutos y semillas como ya fue mencionado para otras áreas de las Sierras Pampeanas (López 2017; Tavarone 2019; entre otros).

Esperamos con este trabajo haber realizado un aporte a la comprensión de la producción y uso de la tecnología cerámica para las ocupaciones humanas del valle de Ongamira hacia finales del Holoceno. Resta realizar estudios sobre una muestra más grande, que también incorpore otros sitios del valle, a los fines de comprender la relación entre las personas y la cerámica en distintos contextos de uso. Además, es necesario incorporar a estas interpretaciones el análisis de fuentes de arcillas para aprender acerca de los modos de producción de pastas y conocer más sobre la manufactura de vasijas por parte de los grupos humanos que poblaron el valle de Ongamira.

\section{AGRADECIMIENTOS}

Queremos agradecer a toda la comunidad del valle de Ongamira, en especial a la familia Castillo que nos recibió y permitió realizar las excavaciones. También queremos agradecer a los miembros del equipo de investigación que colaboraron en las tareas de excavación. Este trabajo fue realizado en el marco de los proyectos PICT-2016-0264 y SECyT 2018-2020 dirigido por la Dra. Roxana Cattáneo y el Dr. Andrés Izeta. Finalmente, queremos agradecer las sugerencias de los evaluadores que ayudaron a mejorar el trabajo.

\section{BIBLIOGRAFÍA}

Alonso, S. y M. F. Gaido

2018. Carta de minerales industriales, rocas y gemas 3163-I Jesús María. Programa Nacional de Cartas Geológicas de la República Argentina 1:250.000. Instituto de Geología y Recursos Minerales, Servicio Geológico Minero Argentino. Boletín 438, Buenos Aires.

Ameghino, F.

1885. Informe sobre el Museo Antropológico y Paleontológico de la Universidad Nacional de Córdoba durante el año 1885. Boletín de la Academia Nacional de Ciencias de Córdoba, Nro. VIII: 347-360.

Argüello de Dorsch, E.

1983. Investigaciones arqueológicas en el departamento Punilla (provincia de Córdoba- República Argentina). Sitio: C. Pun. 39. Comechingonia 1: 41-60.

Bertolino, S., U. Zimmermann, V. Galván y A. G. Laguens

2010. Composición mineralógica y química y posible proveniencia de cerámica pre y post-hispánica del valle del río Copacabana, noroeste de Córdoba. En S. Bertolino, R. Cattáneo, y A. D. Izeta (eds.), La arqueometría en Argentina y Latinoamérica: 35-42. Córdoba, Imprenta de la FFyH-UNC.

Caminoa, J. M.

2016. Un estudio de tecnología lítica desde la antropología de las técnicas: el caso del Alero Deodoro Roca ca. 2970 AP. Ongamira, Ischilín, Córdoba. Oxford, South American Archaeology Series 26. Archaeopress.

Candini, J. C., P. Stuart-Smith, F. Gaido, C. Carignano, R. Miró y H. López

2001. Hoja Geológica 3163-I Jesús María, Provincia de Córdoba. Instituto de Geología y Recursos Minerales, Servicio Geológico Minero Argentino, Subsecretaría de Minería de la Nación. Boletín 314, Buenos Aires.

Cattáneo, G. R., J. M. Caminoa, G. Collo, A. Izeta, M. Rubio, A. Germanier y S. Faudone

2020. Tracking ancient people movements in the Southern Pampean Hills of Argentina by XRF, XRD and 
SEM on quartz lithic technology: a prelimary report. Rendiconti Lincei. Scienze Fisiche e Naturali, https://doi.org/10.1007/s12210-020-00915-9

Cattáneo, G. R. y A. D. Izeta, (eds.)

2016. Arqueología en el Valle de Ongamira. Córdoba, Universidad Nacional de Córdoba.

Cattáneo, G. R., A. D. Izeta y M. Takigami

2013. Primeros fechados radiocarbónicos para el sector B del sitio Alero Deodoro Roca (Ongamira, Córdoba, Argentina). Relaciones de la Sociedad Argentina de Antropología 38: 559-567.

Cattáneo, G. R., M. Martinelli, A. D. Izeta, J. M. Caminoa, T. Costa y A. Robledo

2017. On wedges and bones: Archaeological studies of use-wear and residue analysis from Late Holocene occupations in the Southern Pampean Hills (Alero Deodoro Roca, Córdoba, Argentina). Journal of Archaeological Science, Reports 14: 275-288.

Carignano, C.

1999. Late Pleistocene to recent climate change in Córdoba Province, Argentina: Geomorphological evidence. Quaternary International 57-58: 117-134.

Carosio, S., M. Medina y S. Pastor

2021. Using ceramic petrography to assess human mobility during the Late Prehispanic Period from Sierras of Córdoba (Argentina). Journal of Archaeological Science: Reports 37 102907. https://doi. org/10.1016/j.jasrep.2021.102907

Collo, G., O. Tarditti, J. C. Nóbile, M. Therisod, I. Perassi, C. Wunderlin, A. Germanier, S. Faudone y M. Rustán 2019. Arcillas, cerámica y ciencias. Cicterránea, 4, 12-17. Disponible en: http://cicterra.conicet.unc.edu. ar/wp-content/uploads/sites/6/2020/04/CICTERRANEA-4-WEB.pdf

Costa, T.

2015. Los Humanos, los animales y el territorio. Sus interacciones en el pasado en la Sierras Pampeanas Australes, provincia de Córdoba, Argentina. Tesis Doctoral inédita. Facultad de Filosofía y Humanidades, Universidad Nacional de Córdoba.

Costa, T., A. Robledo y J. Caminoa

2017. Integrando los datos. Las prácticas de las personas a través de las evidencias líticas, antracológica y zooarqueológica recuperadas en el Sector B del sitio ADR (Córdoba, Argentina). Revista Chilena de Antropología 35: 90-112.

Conte, B. y A. Robledo

2020. Aplicación de tecnologías 3D en sitios arqueológicos del valle de Ongamira, Córdoba, Argentina.

Fotogrametría en excavaciones y morteros arqueológicos. Dossier de la Revista del Museo de Antropología 13 (1): 273-280. DOI: http://doi.org/10.31048/1852.4826.v13.n1.23900

Cremonte, M. B.

1983-85. Alcances y Objetivos de los estudios tecnológicos en la Cerámica Arqueológica. Anales de Arqueología y Etnología: 179-217. Mendoza, Universidad Nacional de Cuyo.

1996. Investigaciones Arqueológicas en la Quebrada de la Ciénaga (Dto. Tafí, Tucumán). Tesis Doctoral inédita. Facultad de Ciencias Naturales y Museo, Universidad Nacional de La Plata.

Dantas, M. y G. Figueroa

2008. Análisis tecnológico y funcional del registro cerámico del Valle de Salsacate y pampas de altura adyacentes (provincia de Córdoba, República Argentina). British Archaeological Reports S1869, South American Archaeology Series, Oxford. 
A. Robledo y L. Gasparotti - La tecnología cerámica en ocupaciones del Holoceno TaRdío ...

Dobres, $\mathrm{M}$.

1999. Technology's links and chaînes: the processual unfolding of technique and technician. En M.

Dobres y C. Hoffman (eds.), The Social Dynamics of Technology. Practice, Politics and World Views:

124-146. Washington and London, Smithsonian Institution Press.

2010. Archaeologies of technologies. Cambridge Journal of Economics 34, 103-114.

Dobres, M. y C. R. Hoffman

1994. Social Agency and the Dynamics of Prehistoric Technology. Journal of Archaeological Method and Theory 1(3): 211-258.

Franzen, E.

2016. Análisis sedimentológico y geomorfológico del entorno del Alero Deodoro Roca. Informe Práctica Profesional Supervisada. Universidad Nacional de Córdoba, Facultad de Ciencias Exactas, Físicas y Naturales. Ms.

Freestone, I.

1991. Extending ceramic petrograhy. En A. Middleton y I. Freestone (eds.), Recent developments in ceramic petrology: 399-410. British Museum Ocasional Peper 81. Londres.

1995. Ceramic Petrography. American Journal of Archaeology 99 (1): 111-115.

Gambier, M.

1998. Arqueología de la sierra de San Luis. San Juan. Instituto de Investigaciones Arqueológicas y Museo.

Facultad de Filosofía, Humanidades y Arte, Universidad Nacional de San Juan.

González, A. R.

1952. Antiguo horizonte precerámico en las Sierras Centrales de la Argentina. Runa V: 110-133.

1960. La estratigrafía de la gruta de Intihuasi (Prov. De San Luis, R. A.) y sus relaciones con otros sitios precerámicos de Sudamérica. En Revista del Instituto de Antropología, t. 1, Córdoba.

Hammer Ø., D. A. T. Harper y P. D. Ryan

2001. PAST: Paleontological statistics software package for education and data analysis. Palaeontologia Electronica 4(1): 9pp.

Harris, E.

1991. Principios de Estratigrafía Arqueológica. Barcelona, Editorial Crítica.

Hoffman, C. R.

1999. Intentional Damage as Technological Agency: breaking metals in Late Prehistoric Mallorca, Spain. En M. A. Dobres y C. R. Hoffman (eds.), The social dynamics of technology. Practice, politics and world views: 103-123. Washington. Smithsonian Institution Press.

Izeta, A. D., G. R. Cattáneo, M. Takigami, F. Tokanai, K. Kato \& H. Matsusaki

2016. Estudios cronológicos del Alero Deodoro Roca Sector B (Ongamira, Córdoba, Argentina). En R. Cattáneo \& A. D. Izeta (eds.), Arqueología en el Valle de Ongamira, 2010-2015: 85-100. Córdoba: Universidad Nacional de Córdoba.

Izeta, A. D., R. Cattáneo, A. Robledo y J. Mignino

2017. Aproximación multiproxy a los estudios paleoambientales de la provincia de Córdoba: el Valle de Ongamira como caso. Revista del Museo de Antropología 10: 33-42.

Izeta, A. D., R. Cattáneo, A. Robledo, M. Takigami, M. Yoneda. F. Tokanai y K. Kato

2021. Middle and Late Holocene human occupation chronology in central Argentina. The Ongamira valley case. Radiocarbon. DOI: https://doi.org/10.1017/RDC.2021.22 
Izeta, A. D., T. Costa, S. Gordillo, G. R. Cattáneo y A. Robledo

2014. Los Gasterópodos del sector B del sitio Alero Deodoro Roca, valle de Ongamira (Córdoba. Argentina). Un análisis preliminar. Revista Chilena de Antropología №29 / 1er semestre: 74-80.

Laguens, A. G.

1999. Arqueología del contacto hispano indígena. Un estudio de cambios y continuidades en las Sierras Centrales de Argentina. BAR International Series 801. Oxford, Archaeopress.

Laguens, A. y M. Bonnin

2009. Sociedades Indígenas de las Sierras Centrales, Arqueología de Córdoba y San Luis. Córdoba, Editorial Universidad Nacional de Córdoba.

Lemonnier, P.

1993. Introduction. En: Pierre Lemonnier (ed) Technological choices: Transformation in material cultures since the Neolithic: 1-35. Londres, Routledge.

1992. Elements for an Anthropology of Technology. Michigan, Museum of Anthropology.

Lira, M. S., R. y M. F. Poklepovic

2014. Volcanismo y subvolcanismo cámbrico del sector centro-oeste del batolito de Sierra NorteAmbargasta. En A. Guereschi y R. Martino (eds.), Relatorio del XIX Congreso Geológico Argentino: 217-232. Córdoba, Asociación Geológica Argentina.

López, M. L.

2017. Archaeobotany in central Argentina: macro and microscopic remains at several archaeological sites from early Late Holocene to early colonial times (3000-250 BP). Vegetation History and Archaeobotany, 27 (1): 219-228.

Medina, M. E.

2008. Diversificación económica y uso del espacio en el tardío prehispánico del norte del valle de Punilla, pampa de Olaen y llanura noroccidental (Córdoba, Argentina). Tesis doctoral inédita, Facultad de Filosofía y Letras, Universidad de Buenos Aires.

2010. Tecnología cerámica, subsistencia y uso del espacio en el Tardío Prehispánico de las Sierras de Córdoba (Argentina). Revista Werkén 13: 305-322.

Medina, M., S. Pastor y A. Recalde

2016. The archaeological landscape of late prehispanic mixed foraging and cultivation economy (Sierras of Córdoba, Argentina). Journal of Anthropological Archaeology 42: 88-104.

Menghin, O. A. F. y A. R. González

1954. Excavaciones arqueológicas en el yacimiento de Ongamira, Córdoba (Rep. Arg.) (Nota preliminar). Notas del Museo de La Plata XVII, Antropología 67: 213-274.

Orton, C., P. Tyers y A. Vince

1997. La Cerámica en Arqueología. Crítica, Barcelona. España.

Pastor, S.

2006. Arqueología del Valle de Salsacate y pampas de altura adyacentes (Sierras Centrales de Argentina). Una aproximación a los procesos sociales del período prehispánico tardío (900-1573 d.C.). Tesis Doctoral inédita, Facultad de Ciencias Naturales y Museo, Universidad Nacional de La Plata.

Pereyra Domingorena, L.

2010. Manufacturas alfareras de las sociedades aldeanas del primer milenio d.C. al sur de los valles Calchaquíes. Tesis doctoral inédita, Facultad de Filosofía y Letras, Universidad de Buenos Aires. 


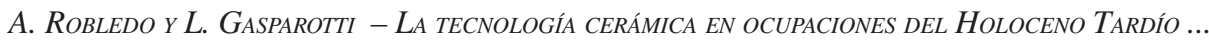

Piovano, E.

1996. Correlación de la Formación Saldán (Cretácico temprano) con otras secuencias de las Sierras pampeanas y de las cuencas Chacoparanense y de Paraná. Revista de la Asociación Geológica Argentina 51 (1) 29-36.

Quinn, P.

2013. Ceramic Petrography: The Interpretation of Archaeological Pottery y Related Artefacts in Thin Section. Archeopress. Oxford, Gordon House.

Robledo, A.

2016. Estudios antracológicos en los espacios de combustión del Alero Deodoro Roca - Ongamira (Córdoba). South American Archaeology Series 25. Archaeopress. ISBN 9781784913441.166 p.

2020. Arqueología en el Valle de Ongamira (Dptos. de Ischilin y Totoral, Córdoba, Argentina). Paisajes y lugares de las sociedades cazadoras-recolectoras holocénicas. Tesis doctoral inédita, Universidad Nacional de Córdoba.

Robledo, A., R. Cattáneo y B. Conte

2018. Tecnología lítica y uso del espacio en el alero Parque Natural Ongamira 1 (Depto. Ischilín, Córdoba, Argentina). Anales de Arqueología y Etnología, vol. 72, No 2: 219-244.

Rocchietti, A. M. y F. Ribero

2017. Cazadores prehispánicos de la comarca de Achiras, provincia de Córdoba: Análisis de oportunidad. Revista de Sociedades de Paisajes Áridos y Semi-áridos, Vol X: 9-93.

2018. La formación arqueológica ceramolítica en los depósitos holocénico-tardíos en la sierra de los Comechingones. Revista de Sociedades de Paisajes Áridos y Semi-Áridos, Vol. XI: 10-31.

Roldán, F., D. Rivero y S. Pastor

2005. Las Sierras Centrales durante el Holoceno: perspectivas desde el Alto III (Pampa de Achala, Provincia de Córdoba). Actas del XIII Congreso Nacional de Arqueología Argentina IV: 277-286. Córdoba.

Rye, O.

1988 [1981]. Pottery Technology. Principles and Reconstruction. Manuals on archaeologyn ${ }^{\circ} 4$. Australian National University. Washington, Taraxacum.

Serrano, A.

1945. Los comechingones. Sobre Aborígenes Argentinos I. Instituto de Arqueología, Lingüística y Folklore de la Universidad Nacional de Córdoba.

Sinopoli, C.

1991. Approaches to Archaeological Ceramics. Nueva York, Plenum Press.

Tavarone, A.

2019. Late Holocene plant use in lowland central Argentina: Microfossil evidence from dental calculus. Journal of Archaeological Science: Reports 26: 101895.

Traktman, M., G. Sario, M. Salvatore y P. Anzil

2020. Clasificación de grupos y análisis petrográfico: hacia una caracterización de los conjuntos cerámicos de la cuenca del Río Copacabana (Ischilín, Córdoba,Argentina). En Relaciones de la SociedadArgentina de Antropología XLV (1), enero-junio 2020: 111-130.

Zagorodny, $\mathrm{N}$.

2000. Descripción de una técnica expeditiva de análisis cerámico. Contribución Arqueológica 5: 259-266.

Zárate, M.

2016. Explorando la historia geológica del Alero Deodoro Roca. En R. Cattáneo y A. D. Izeta (eds.), Arqueología en el Valle de Ongamira, 2010-2015: 43-56. Córdoba, Universidad Nacional de Córdoba. 
